Madrygal. Revista de Estudios Gallegos

ISSN: $1138-9664$

\title{
La deixis personal en algunas cartas de Rosalía de Castro y Emilia Pardo Bazán desde la gramática funcional del discurso ${ }^{1}$
}

\author{
Patricia Fernández Martín ${ }^{2}$
}

Recibido: 11 de febreiro de 2019 / Aceptado: 21 de outubro de 2019

Resumen. El objetivo del artículo es comparar la deixis personal de las cartas escritas por Rosalía de Castro a Manuel Murguía, por un lado, con las escritas por Emilia Pardo Bazán dirigidas a Benito Pérez Galdós, por otro. Para ello, se utiliza la gramática funcional del discurso (GFD) para analizar la deixis personal que alude a los interlocutores en la comunicación misiva, tomando como punto de partida el concepto de referencia exofórica. Así, en la primera parte, se presenta el marco teórico que atiende a tres pilares: la historia del corpus lingüístico seleccionado, las premisas metodológicas de la GFD y la descripción de los fenómenos lingüísticos analizados (elementos deícticos de persona que aparecen en las firmas, en las direcciones y en el cuerpo del texto, siempre que aludan a los interlocutores del intercambio epistolar). En la segunda parte, se ofrece el análisis de los textos en el nivel interpersonal, en el nivel representacional y en el nivel morfosintáctico, de acuerdo con los primordiales parámetros de la GFD. La principal conclusión defiende que la relación De Castro-Murguía denota un profundo cariño y una amplia confianza que, con constantes fluctuaciones, toma la forma de pasión amorosa y amistad en la relación Pardo Bazán-Pérez Galdós.

Palabras clave: deixis personal; género epistolar; Rosalía de Castro; Emilia Pardo Bazán.

\section{[gal] A deíxe persoal nalgunhas cartas de Rosalía de Castro e Emilia Pardo Bazán desde a Gramática Funcional do Discurso}

Resumo. O obxectivo do artigo é comparar a deixe persoal das cartas escritas por Rosalía de Castro e dirixidas a Manuel Murguía, por unha banda, con algunas das escritas por Emilia Pardo Bazán e dirixidas a Benito Pérez Galdós, por outra. Para isto, emprégase a gramática funcional do discurso (GFD), pois serve para analizar a deíxe persoal que alude aos interlocutores da comunicación misiva, tendo en conta como punto de partida o concepto de referencia exofórica. Así, na primeira parte, preséntase o marco teórico, que consta de tres piares: a historia do corpus lingüístico seleccionado, as premisas metodolóxicas da GFD e a descrición dos fenómenos lingüísticos analizados (certos elementos deícticos de persoa que aparecen nas sinaturas, nas direcións e no corpo do texto, sempre que aludan aos interlocutores do intercambio epistolar). Na segunda parte, ofrécese unha análise dos textos no nivel interpersoal, no nivel representacional e no nivel morfosintáctico, de acordo cos primordiais parámetros da mencionada GFD. A principal conclusión é que a relación De Castro-Murguía amosa un profundo agarimo e unha ampla fiúza que, con constantes flutuacións, se converte nunha paixón amorosa e penetrante amizade no caso da relación Pardo Bazán-Pérez Galdós.

Palabras chave: deíxe persoal; xénero epistolar; Rosalía de Castro; Emilia Pardo Bazán.

\section{[en] Person Deixis in some Letters Written by Rosalía de Castro and Emilia Pardo Bazán Studied from the Functional Discourse Grammar}

Abstract. The aim of this paper is to compare the person deixis of the letters written by Rosalía de Castro to Manuel Murguía, on the one hand, with the ones written by Emilia Pardo Bazán addressed to Benito Pérez Galdós, on the other.

1 Este trabajo se enmarca dentro del Proyecto I+D del Ministerio de Economía y Competitividad titulado "Procesos de gramaticalización en la historia del español (V): gramaticalización, lexicalización y análisis del discurso desde una perspectiva histórica” (FFI2015-64080), dirigido por el Dr. Francisco Javier Herrero Ruiz de Loizaga, de la Universidad Complutense de Madrid.

2 Universidad Autónoma de Madrid. Grupo de investigación Discourse Analysis and Intercultural Communication (UAM SOC PR-009). Departamento de Filologías y su Didáctica, Facultad de Formación de Profesorado y Educación.

Correo-e: patricia.fernandez01@uam.es 
For this, the Functional Discourse Grammar (FDG) is used to analyze the personal deixis which refers to the interlocutors in the epistolar communication, taking as a starting point the concept of exophoric reference. Thus, in the first part, the theoretical framework is exposed: the history of the chosen linguistic corpus; the main factors of FDG and the description of the linguistic phenomena to be analyzed -person deictics which appear in the signatures, in the directions and in the body of the text, if they allude to the interlocutors of the epistolary exchange. In the second part, the analysis is offered at the interpersonal level, at the representational level and at the morphosyntactic level, according to the FDG's primary parameters. The main conclusion highlights that the relationship De Castro-Murguía denotes a deep affection and a wide confidence that, with constant fluctuations, becomes loving passion and friendship in the relationship Pardo Bazán-Pérez Galdós.

Keywords: Personal Deixis; Epistolar Genre; Rosalía de Castro; Emilia Pardo Bazán.

Sumario. 1. Introducción. 2. Marco teórico. 2.1. La gramática funcional del discurso. 2.2. Algunas cartas de Rosalía de Castro y de Emilia Pardo Bazán. 2.3. Las referencias personales. 3.1. Nivel interpersonal (I): el tratamiento al lector de las cartas de Rosalía. 3.2. Nivel interpersonal (II): el tratamiento al lector de las cartas de Emilia. 3.3. Nivel representacional (I): la percepción del yo en las cartas de Rosalía. 3.4. Nivel representacional (II): la percepción del yo en las cartas de Emilia. 3.5. Nivel morfosintáctico (I): la modalidad subjetiva en las cartas de Rosalía. 3.6. Nivel morfosintáctico (II): la modalidad subjetiva en las cartas de Emilia. 4. Interpretación de los datos. 5. Conclusiones. 6. Referencias bibliográficas.

Como citar: Fernández Martín, P. (2019): "La deixis personal en algunas cartas de Rosalía de Castro y Emilia Pardo Bazán desde la Gramática Funcional del Discurso", en Madrygal. Revista de Estudios Gallegos 22, pp. 135-159.

\section{Introducción}

Aunque se ha avanzado mucho en la incorporación del discurso femenino a los estudios literarios desde una perspectiva histórica, como muestra el reciente companion research de Baranda Leturio y Cruz (2018), no son todavía excesivamente frecuentes los estudios que abarquen el mismo tipo de discurso desde una perspectiva fundamentalmente lingüística, como modélicamente se hace en los cuidados trabajos editados por Almeida Cabrejas, Díaz Moreno y Fernández López (2017), tal vez debido, precisamente, a las escasas ediciones críticas fiables de los textos femeninos que permitan efectuar análisis lingüísticos aceptables (Cruz 2009) los cuales, a su vez, son igualmente necesarios para conseguir ediciones críticas fiables.

Este círculo vicioso puede ejemplificarse de forma totalmente trivial echando un simple vistazo al catálogo de la prestigiosa Biblioteca Clásica de la Real Academia Española, pues de las primeras ciento once obras editadas solo seis han sido escritas por mujeres (un 5,4\%), una del siglo XVI, otra del siglo XVII y cuatro del siglo XIX: El libro de la vida de santa Teresa de Jesús (n ${ }^{\circ} 35$ de la colección); Primero sueño y otros poemas de sor Juana Inés de la Cruz (n $\left.{ }^{\circ} 75\right)$; La gaviota de Fernán Caballero ( $\mathrm{n}^{\circ}$ 92), Autobiografia y otras páginas de Gertrudis Gómez de Avellaneda (n ${ }^{\circ}$ 94), En las orillas del Sar y otros poemas de Rosalía de Castro (n 99) y Los Pazos de Ulloa de Emilia Pardo Bazán (nº 111).

Estas dos últimas autoras son, precisamente, las que constituyen el objeto de nuestro estudio que, sin embargo, no va a tomar en consideración sus obras puramente literarias sino que va a centrarse en las cartas que cada una dirigió a sus respectivas parejas (Manuel Murguía, en el caso de Rosalía de Castro; Benito Pérez Galdós, en el caso de Emilia Pardo Bazán) durante más de veinte años. Al hacerlo, además, se van a aplicar los pilares metodológicos de la gramática funcional del discurso, pues resulta una potente herramienta para guiar los senderos de la investigación lingüística del texto. Lo que pretendemos con todo esto es, naturalmente, ampliar el conocimiento sobre cuestiones pragmáticas en un tipo de texto que, por su carácter dialógico, se presta con facilidad a ello (Almeida Cabrejas, Díaz Moreno y Fernández López 2017; Fernández Martín 2018) a la vez que ofrecemos, en la medida de nuestras posibilidades, una manera bastante sistemática de hacerlo (Hengeveld y Mackenzie 2008).

La elección de estas dos féminas se debe a tres motivos esenciales. En primer lugar, como se ha dicho, no son muchos los textos escritos por mujeres gallegas que hayan sido publicados $y$ que incluso se encuentren de forma abierta en la red, como sucede con las cartas de Rosalía en el Consello da Cultura Galega y con algunas de Emilia en el Archivo de la Real Academia Española. Ofrecer este tipo de accesibilidad, pese a todos los inconvenientes que pueda suponer (Patiño Eirín 2013), siempre juega a favor de una investigación que está constantemente atada a la limitación de recursos humanos y materiales.

En segundo lugar, ambas son mujeres coetáneas que proceden de la misma zona geográfica, aunque pertenezcan a ámbitos socioculturales distintos. La comparabilidad de sus textos puede llevarse a cabo aplicando un esquema de análisis de los respectivos contextos de producción en que se crean las cartas (Nystrand, Himley y Doyle 1986), que ha sido ya empleado con fines didácticos en otro lugar (Fernández Martín 2016). 
En efecto, dicho contexto de producción consta de tres niveles: el macrocontexto sociohistórico, conformado por aquellos factores sociológicos que pueden ser relevantes para comprender al autor; el entorno que rodea a cada situación comunicativa plasmada en los diversos productos textuales estudiados; y el microcontexto, que es el cotexto estrictamente lingüístico.

El primer nivel, el macrocontexto, nos permite aprehender los elementos que durante una interacción tienden a permanecer estables y, por ello, ser extrasituacionales (Van Dijk 2008: 111-216). Por cuestiones metodológicas, los reducimos al grupo social (profesión), género o sexo, edad, sociedad de origen e identidad lingüística (Salzmann 2007: 217-242). Creemos que, excepto una mínima diferencia en la clase social (de la aristocracia de Emilia a la hidalguía de Rosalía hay menos distancia que entre la primera y la clase obrera, por ejemplo), nuestras dos mujeres coinciden en todo, ya que ambas son escritoras gallegas, pertenecen al género femenino, tienen una edad similar cuando escriben las cartas (de los treinta a los cincuenta aproximadamente en el caso de la padronesa; de los treinta a los sesenta aproximadamente en el caso de la coruñesa) $\mathrm{y}$, en este momento de sus vidas, emplean el castellano para comunicarse con sus respectivos interlocutores.

El segundo nivel, el entorno, está constituido por los aspectos intrasituacionales que dependen directamente de la situación comunicativa, aunque se centren también en los interlocutores. Para nuestros intereses, basta con reducirlos a los de la clásica lingüística del texto (Beaugrande y Dressler 1997): intencionalidad, aceptabilidad, informatividad, situacionalidad e intertextualidad (Nystrand, Himley y Doyle 1986; Van Dijk 2008). Creemos que son comparables porque estos factores, aplicados a los respectivos conjuntos de misivas, son similares. Así, ambas tienen diversas intenciones dependiendo de los momentos en que se escriba cada carta: agradar al otro, mantener viva la relación, recriminarle su ausencia o su falta de atención... Igualmente, estos textos suelen ser altamente relevantes (informatividad) porque implican respuestas por parte de los lectores, sea yendo directamente a visitarla, sea escribiéndole rápidamente alguna carta en correspondencia (aceptabilidad). Esta relevancia comunicativa se relaciona, precisamente, con la situación en que toda la correspondencia tiene lugar, de manera que la informatividad de una sola carta no puede comprenderse sin la situacionalidad de todo el epistolario. La intertextualidad, igualmente, es compartida, pues no solo ambas emplean las normas básicas del discurso epistolar (lo que entronca con la tradición textual correspondiente) sino que, además, en numerosas ocasiones una carta alude a otra suya (o no), en un afán de concatenar discursos que se rompen por causas de fuerza mayor. Además, naturalmente, ambas viven en épocas muy próximas literariamente que, por tanto, facilitan esa comunicación entre los distintos textos, como muestra, de hecho, la carta de Emilia Pardo Bazán en la que cita un poema de Rosalía o todos estos personajes galdosianos que ella misma emplea para denominarlo.

En el tercer nivel de análisis encontramos el cotexto, es decir, lo estrictamente lingüístico que nosotros, discursivamente, reducimos a la cohesión y la coherencia. Al tratarse ambos corpus de cartas personales, parece evidente que el funcionamiento estructural (saludo, introducción, cuerpo del texto, despedida, cierre) sea bastante similar (Almeida Cabrejas, Díaz Moreno y Fernández López 2017).

Finalmente, siempre hay una decisión personal en toda elección discursiva. Cada investigadora debe empatizar no solo con todos y cada uno de sus actos de habla sino también con todos y cada uno de sus actos de escucha o, en nuestro caso, de lectura, pues estos contribuyen, naturalmente, a conformar su propia identidad profesional de la que, al final, difícilmente logra escapar.

Se divide, pues, el trabajo en tres partes. En la primera, presentamos el marco teórico, que atiende a tres pilares esenciales: unas nociones sobre el corpus lingüístico seleccionado ( 2.1$)$; las principales premisas de la gramática funcional del discurso (\$2.2); y el objeto de la lengua en que centraremos el estudio (\$2.3). En la segunda parte, se ofrece el exhaustivo análisis de los textos en el nivel interpersonal $(\S \S 3.1$, $3.2)$, en el nivel representacional $(\$ \S 3.3,3.4)$ y en el nivel morfosintáctico $(\S \S 3.5,3.6)$. En el penúltimo apartado del trabajo se lleva a cabo, en la medida de lo posible (pues los corpus son cuantitativamente muy distintos), una comparación entre ambas escritoras.

Cabe por último hacer una alusión a las ediciones empleadas. Las ocho cartas de Rosalía de Castro dirigidas a su esposo Manuel Murguía han sido citadas por la edición que, realizada por Helena González Fernández, Maria Xesús Lama López y María do Cabreiro Rábade Villar, ofrece el Consello da Cultura Galega 
en su página web, pues en seis de los ocho casos se muestra también la versión original manuscrita. Siendo conscientes de sus limitaciones (Patiño Eirín 2013), la edición utilizada para las misivas de Emilia Pardo Bazán es la realizada por Parreño y Hernández (2013), que incluye las 92 cartas escritas a Benito Pérez Galdós, además de una primera epístola escrita por este a aquella. Cada vez que citemos a estas editoras, por tanto, nos estamos refiriendo a la introducción de la susodicha edición, reflejada en las fuentes primarias de la bibliografía final. No obstante, se ha consultado igualmente la edición digital de la Biblioteca Virtual Miguel de Cervantes, que se basa a su vez en las Obras completas de Manuel Arroyo Stephens (Madrid, Fundación José Antonio Castro, 1993, t. II, pp. 601-614) y la Obra completa de Mauro Armiño (Madrid, Akal, 1980, t. III, pp. 531-549) que probablemente se remontan a la primera edición de las epístolas de Juan Naya.

\section{Marco teórico}

Como se ha dicho, son tres los pilares esenciales del trabajo: i) el valor del corpus epistolar escrito por dos mujeres del siglo XIX como son Rosalía de Castro y Emilia Pardo Bazán (\$2.1); ii) las premisas metodológicas $(\$ 2.2)$, a caballo entre la gramática funcional de $\mathrm{Ha}-$ lliday (Halliday y Mathiessen 2014) y la gramática funcional del discurso defendida por Hengeveld y Mackenzie (2008); y iii) el objeto de estudio ( $\$ 2.3)$, esto es, toda referencia exofórica o deixis (personal), en tanto permite representar en la lengua las relaciones establecidas socialmente entre los interlocutores que participan en el discurso.

\subsection{Algunas cartas de Rosalía de Castro y de Emilia Pardo Bazán}

A pesar de la comparabilidad de sus textos, las dos mujeres de las que vamos a hablar en este trabajo eran muy diferentes (Albert Robatto 2002). Rosalía de Castro (1837-1885) parecía tener una personalidad "fuerte, contestataria, difícil, irascible, de ideas nuevas y radicales en aquel tiempo" (Davies 2014: 41), con dos guías fundamentales como eran el independentismo gallego y la autonomía femenina, pero nunca mantuvo una vida pública como sí hicieron otras mujeres de su época, empezando por la misma Emilia Pardo Bazán. De Castro, pese a todas las extravagancias que pudieran conformar su vida (entre las que podría encontrarse simplemente el deseo juvenil de ser escritora), formaba parte de un colectivo que precisaba guiarse por las normas sociales, los hidalgos, que quizá reivindicaba el cambio desde la palabra pero luego no podía, por motivos diversos, llevarlo fácilmente a la práctica (Barreiro Fernández 2014; Davies 2014). Uno de esos impedimentos, naturalmente, se encontraba en el hecho de estar casada y de tener que desempeñar el papel típico de la mujer, esto es, cuidar de los siete hijos (dos fallecidos en época prematura) que, como sus obras, permitirían la continuación de la estirpe De Castro-Murguía (Mayoral 1986; Albert Robatto 2002).

Es, precisamente, esta relación la que nos interesa resaltar aquí, pues resulta fundamental para comprender las ocho cartas fragmentadas que constituyen una parte de nuestro corpus. Se redactaron entre 1861 y 1881 y todas estaban dirigidas al que desde el 10 de octubre de 1858 es su marido, Manuel Martínez Murguía (Costa Clavell 1967; Mayoral 1986). A él puede agradecerse que previera un talento literario como fue el de Rosalía o que, incluso, la animara en ocasiones a escribir en gallego (de lo que ella se queja amargamente, por ejemplo, en la octava de las cartas que componen el corpus), si bien podemos también reprocharle que al final de su vida quemara las epístolas que ella le había escrito. Los motivos para hacerlo podrían ser bien preservar su propia imagen, para ocultar así lo humillante o vergonzoso que pudieran tener para él esas cartas; bien defender la imagen de Rosalía, pues no era adecuado a ella que se supiera lo sola, triste y deprimida que estuvo, lo que le necesitaba y le quería, las estrecheces económicas que pasaron (Mayoral 1986; García Montero 2014), por no hablar, naturalmente, de su desgraciadamente naturaleza enfermiza (Álvarez Ruiz de Ojeda 2016).

Frente a ella, Emilia Pardo Bazán (18511921) convierte la fuerza en hechos sin explicarlos a priori. Se atrinchera en su poder de clase para modificar su papel de género cuando, por ejemplo, decide separarse de su marido tras quince años de matrimonio (con tres hijos), tal vez a raíz del escándalo que produce la publicación de La cuestión palpitante, en 1883. Como Rosalía, ella también desea ser escritora profesional aunque nunca compartiría sus ideales nacionalistas (Hermida 1989; Albert Robatto 2002). Busca convertir su espacio privado escriturario en un amplio espacio de reconocimiento público que le permita un sustento. Y, a diferencia de la padronesa, 
doña Emilia lo consigue gracias a otra mujer, su propia madre, que le facilita suficiente apoyo para mantener a sus hijos y permitir que ella se dedique plenamente a la literatura. Desde su privilegiada posición de aristócrata, mantiene una constante (y a veces infructuosa) lucha literaria en defensa de la mujer, cuya esencia sabe que se basa en la autonomía económica. Su empeño feminista es tal que (con) mueve a la prensa de todo el país entre 1889 y 1912 por un sillón en la Real Academia Española que nunca consigue (Panero Menor 1989; Haro Fernández 2011; Virtanen 2016). La diferencia de clase entre ellas, entonces, parece crucial para entender los distintos tejidos a que dieron lugar sus vidas, comenzando por la misma configuración de sus visiones del mundo.

La segunda gran parte del corpus, pues, la conforman las 92 cartas escritas por la condesa a Benito Pérez Galdós entre 1883 y 1915 que, en principio, tomamos como verdaderamente autobiográficas y no como textos de ficción (Panero Menor 1989). Estos textos, que permiten un análisis mayor que las cartas de Rosalía, exponen una relación dividida claramente en tres fases: a) entre 1883 y 1887 , la relación entre ellos es la prototípica de la época entre una alumna y su maestro (epístolas 1-21 de nuestra edición); b) entre 1888 y 1889 se muestran sentimientos de amor, de ruptura y de reconciliación (epístolas 22-63) y c) entre 1890 y 1915 se produce un distanciamiento convertido en una amistad que nunca desapareció (epístolas 64-93). La edición empleada, recuérdese, es la efectuada por Parreño y Hernández (2013), en la que se ha incluido una primera carta escrita por el mismo Benito Pérez Galdós que, obviamente, no forma parte de nuestro análisis.

\subsection{La gramática funcional del discurso}

La gramática funcional del discurso (en adelante, GFD) es un modelo de gramática de tipo modular, en el que se parte de arriba abajo, desde la pragmática (nivel interpersonal) a la semántica (nivel representacional) y de estos a la morfosintaxis (nivel morfosintáctico) y la fonología (nivel fonológico), resultados del proceso de codificación. Se parte del componente conceptual, inserto en el componente contextual y, a través del componente gramatical, constituido por los cuatro niveles mencionados (interpersonal, representacional, morfosintáctico y fonológico), se llega al componente de salida. El núcleo que constituye el foco de atención de la GFD es, precisamente, el componente gramatical (Hengeveld y Mackenzie 2008: §1.2.5; Alturo 2010a).

Se asume, en cualquier caso, que esta estructuración no considera cada módulo un compartimento estanco, pues hay una dinámica de interacción entre ellos. La concepción compleja del funcionamiento del lenguaje implica, precisamente, la necesidad de dividirlo en módulos con el simple objetivo de poder analizarlo, nunca de entenderlo así desde una perspectiva esencialmente ontológica (Hengeveld y Mackenzie 2008).

Además, para la GFD la unidad básica de análisis es el acto del discurso, definido como la unidad mínima de comportamiento comunicativo que se puede identificar (Ibid. §2.4). Dado que pretendemos tratar el conjunto de cartas que analizamos a continuación como una tradición discursiva muy concreta, esto es, un determinado tipo de epístola como es la personal (Almeida Cabrejas, Díaz Moreno y Fernández López 2017; Fernández Martín 2018), entendemos que cada una de las cartas escritas por Rosalía de Castro y Emilia Pardo Bazán es, per se, un acto de discurso (Hengeveld y Mackenzie 2008: $\S 2.3$ ).

Así pues, dentro de los actos discursivos que nos ocupan, el nivel interpersonal, el puramente pragmático, comprende todos aquellos fenómenos lingüísticos que reflejan la interacción entre los interlocutores (Ibid. 46). En nuestro análisis, este nivel está representado por la referencia exofórica limitada a la deixis personal, es decir, a la que evoca directamente al interlocutor de cada epístola (Ibid. §§2.6, 2.8.3; Alturo 2010a) que, por tanto, se va a ver reflejada, lingüísticamente, en las fórmulas de tratamiento y los vocativos $(\S \S 3.1,3.2)$.

De forma complementaria al evocar al tú (función pragmática), en el nivel representacional tiene lugar la denotación del yo (función semántica), que ocurre cuando desde la intención subyacente al componente conceptual se pretende aludir, entre otros, a individuos que ocupan una porción concreta de espacio (Hengeveld y Mackenzie 2008: $\S \S 2.8 .2,3.8$; Alturo 2010a). Este nivel se representa, en nuestro análisis, mediante aquellos sintagmas nominales que refieren a las propias escritoras, normalmente plasmados en su firma $(\S \S 3.3,3.4)$.

El tercer y último nivel que es objeto de análisis aquí es el morfosintáctico, que toma forma, en nuestro estudio, en aquellos ejemplos 
escritos por Rosalía y por Emilia en los que hay una perífrasis verbal con expresión de la modalidad o de la no factualidad (Fernández de Castro 1999) en primera persona $(\S \S 3.5$, 3.6).

Esto se debe, en primer lugar, a que las perífrasis están formadas por un verbo que necesariamente ha sido codificado mediante un proceso de auxiliación (Veyrat Rigat 1993; Garachana Camarero 2017a), a lo que cabe añadir que ofrezca significado léxico en el nivel representacional y que carezca de valor semántico en el interpersonal (Hengeveld y Mackenzie 2008: §4.6). En segundo lugar, este grupo de perífrasis aporta un matiz, como es el de la modalidad (Fernández de Castro 1999; Fernández Martín 2014, 2015; Garachana Camarero 2017b) que, dado su valor de expresión de un estado de cosas, puede ser incluido en el nivel representacional (Hengeveld y Mackenzie 2008: §3.5), pero también dentro del estrictamente gramatical si se percibe la morfosintaxis como su único medio de expresión en lengua española (Halliday y Mathiessen 2014: $\S 10.3)$. Por último, en tercer lugar, se da una perfecta combinación entre la característica propiamente subjetiva de los verbos modales (Traugott y Dasher 2002: §3.2.5) y la susodicha primera persona, pues esta permite una referencia directa a la escritora (que incluye al lector, si está en plural), que enfatiza el valor subjetivo que ya tienen aquellos por sí mismos (Hengeveld y Mackenzie 2008: 2.6; Alturo 2010a).

En síntesis, pues, seleccionamos los objetos de nuestro análisis asumiendo el discurso como unidad mínima de estudio y, por tanto, entendiendo como esencial la interacción que tiene lugar en él, aunque nos centremos, en exclusiva, en el estudio de la voz femenina. Queda patente, pues, lo útil de la propuesta de la GFD para nuestro objetivo, si bien somos conscientes de que la armónica interacción entre los distintos niveles propuestos conlleva una natural complejidad en la estricta distinción de los elementos lingüísticos que en cada caso los componen.

\subsection{Las referencias deícticas personales}

Para comprender la naturaleza del objeto lingüístico que analizamos aquí conviene asumir que la referencia es una de las maneras de construir la cohesión gramatical del discurso $y$, por tanto, de facilitar su coherencia. Puede ser endofórica, si el referente a que alude la expresión lingüística se encuentra en el mismo texto; o exofórica, si refiere a un elemento ajeno al discurso, es decir, que forma parte de la realidad extralingüística. Dentro de la exofórica, existe una relación deíctica si se alude a elementos sociocognitivamente relevantes para los que participan en el contexto de situación (Van Dijk 2008), sean espaciotemporales, sean personales, sean comparativos (Halliday y Mathiessen 2014: §9.4; Cuenca 2010). En sentido estricto, por tanto, todo elemento puramente lingüístico que haga alusión a otro que se encuentra en el mismo texto será endofórico, pero siempre será exofórico el referente último que se encuentre en la realidad más allá del discurso (Halliday y Mathiessen 2014: $\S \S 9.2,9.4 .1)$.

Entonces, si asumimos que en todo discurso, especialmente en el epistolar, los elementos más relevantes son los interlocutores, estos pueden ser estudiados desde dos perspectivas lingüísticas de análisis textual que conjugan lo endofórico (pues contribuyen al tejido textual cuando son mencionados) con lo exofórico (pues no forman parte del texto stricto sensu). Por una parte, dado que las cartas no dejan de ser, como se ha dicho, un género dialogado, cabe asumir la necesaria existencia de constantes referencias al yo escritor y al tú lector (Cuenca 2010: 17-20), lo que convierte el análisis lingüístico en un estudio de la deixis personal en el español del siglo XIX (Almeida Cabrejas, Díaz Moreno y Fernández López 2017; Fernández Martín 2018), representado por el estilo de Rosalía de Castro y de Emilia Pardo Bazán. En concreto, se tendrán en cuenta, entonces, las fórmulas de tratamiento directo al interlocutor, por un lado (Sáez Rivera 2014); $\mathrm{y}$, por otro, la concepción de la propia voz de las escritoras, especialmente cuando expresen cierto tipo de modalidad subjetiva, como la que ejemplifican algunas perífrasis verbales a cuyo análisis en primera persona nos limitamos.

Precisamente, esta es, por otra parte, la segunda manera en que nos encontramos la alusión al yo, pues en numerosas ocasiones las escritoras tienden a hablar de sí mismas en tercera persona (Fernández Martín 2018), como ocurre, por ejemplo, al firmar. Este mecanismo, que desde el nivel representacional alude a una realidad exofórico-deíctica, desde el nivel morfosintáctico deja sin embargo de ser deíctico, porque técnicamente no incluye en el discurso ni al hablante ni al oyente, sino que pasa a referirse al primero como si no 
formara parte del contexto que comparte con el segundo (Nystrand 1986).

En síntesis, concebimos la deixis personal como la alusión a los interlocutores (yo, tú) en el discurso. En tanto ajenos al propio texto, se entiende que sus menciones en él serán siempre exofóricas, pero no siempre que una alusión sea exofórica tendrá por qué ser, además, deíctica: para ello, su referente deberá formar parte de la situación en que se enuncia dicho texto.

\section{Análisis e interpretación}

Como se ha indicado, la primera parte del análisis de corpus se corresponde con el nivel interpersonal, dentro de la GFD descrita anteriormente (\$2.1). En concreto, el estudio se centra en las fórmulas de tratamiento que Rosalía, por un lado (§3.1), y Emilia, por otro (§3.2), emplean para dirigirse a sendos interlocutores.

En la segunda parte del presente análisis, nos introducimos en el nivel representacional del lenguaje $(\S \S 3.3,3.4)$, para estudiar los mecanismos fóricos de claro significado léxico-referencial que emplean las mencionadas mujeres para referirse a sí mismas.

El tercer nivel, el morfosintáctico, es representado mediante algunas perífrasis verbales no factuales (Fernández de Castro 1999: 150-200), solamente cuando aparecen expresadas en primera persona $(\S \S 3.5,3.6)$, pues contribuyen a expresar la modalidad subjetiva de las escritoras (Halliday y Mathiessen 2014: $\S 4.2 .2 .2)$.

\subsection{Nivel interpersonal (I): el tratamiento al lector de las cartas de Rosalía}

El tratamiento a Manuel Murguía, tomado entonces como referente del análisis, se puede dar en las cartas de Rosalía de tres maneras distintas: en las fórmulas de tratamiento, directamente relacionadas con la dirección de la carta; en los vocativos que aparecen en el cuerpo del texto y en el empleo de otros sintagmas que implícitamente están aludiendo a él.

Las cartas cuyas direcciones conservamos comienzan con "Mi querido Manolo" (cartas 1, 3, 6 y 8) o "Querido Manolo" (carta 5). Todas ellas muestran una normal familiaridad que se convierte en un claro tuteo al lector:

Mi querido Manolo: No debía escribirte hoy, pues tú, que me dices lo haga yo todos los días, escaseas las tuyas cuanto puedes, pues casualmente los dos días peores que he tenido, hasta me aconteció la fatalidad de no recibir carta tuya. Ya me vas acostumbrando, y como todo depende de la costumbre, ya no me hace tanto efecto; sin embargo, estos días en que me encuentro enferma, como estoy más susceptible, lo siento más. Te perdono, sin embargo, aunque sé que no tendrías hoy otro motivo para no escribirme que el de algún paseíto con Indalecio, u otra cosa parecida. (Carta 3)

Esta familiaridad se deja ver, igualmente, en los vocativos detectados, pues hay dos muy interesantes dentro del cuerpo del texto:

Pobrecito mío, ¿qué dirás de mi mal humor? (Carta 3)

Adiós, querido de mi corazón, y haz cuanto te sea posible por que esta separación no dure mucho. (Carta 5)

Finalmente, la alusión al lector-esposo cuyo deber es, para ella, apoyarla especialmente en sus peores días, se aprecia en el siguiente fragmento, que sin duda alguna ayuda a ejemplificar igualmente el grado de familiaridad existente entre los interlocutores:

Tú ya sabes que cuando estoy enferma me pongo de un humor del diablo, todo lo veo negro, y, añadiendo a esto que no te veo y nuestras circunstancias malditas, cien veces, con una bilis como la mía, precisamente cuando va dirigida a la persona que más se quiere en el mundo, y a la única a quien se le pueden decir estas cosas. Perdóname, pues, y sobre todo no me hagas caso. (Carta 3)

Las cartas de Rosalía de Castro dirigidas a Manuel Murguía, por tanto, ilustran a la perfección la relación existente entre una mujer que aprecia a su marido y que, precisamente por ello, se siente con la confianza suficiente como para tratarlo de tú a tú, de forma directa y sin dejar de ser ella misma.

\subsection{Nivel interpersonal (II): el tratamiento al lector de las cartas de Emilia}

El tratamiento que Emilia Pardo Bazán dirige a Benito Pérez Galdós oscila entre la mayor de las formalidades, cuando emplea $u s$ ted (que siempre escribe "V.", excepto en tres ocasiones en todo el epistolario, en que escribe "Vd.", cartas 25 y 92), y la mayor de las familiaridades, cuando utiliza el tú e, incluso, el vos, este último como marca de complicidad y cariño. En el siguiente gráfico puede verse el uso de usted en la correspondencia de Emilia: 


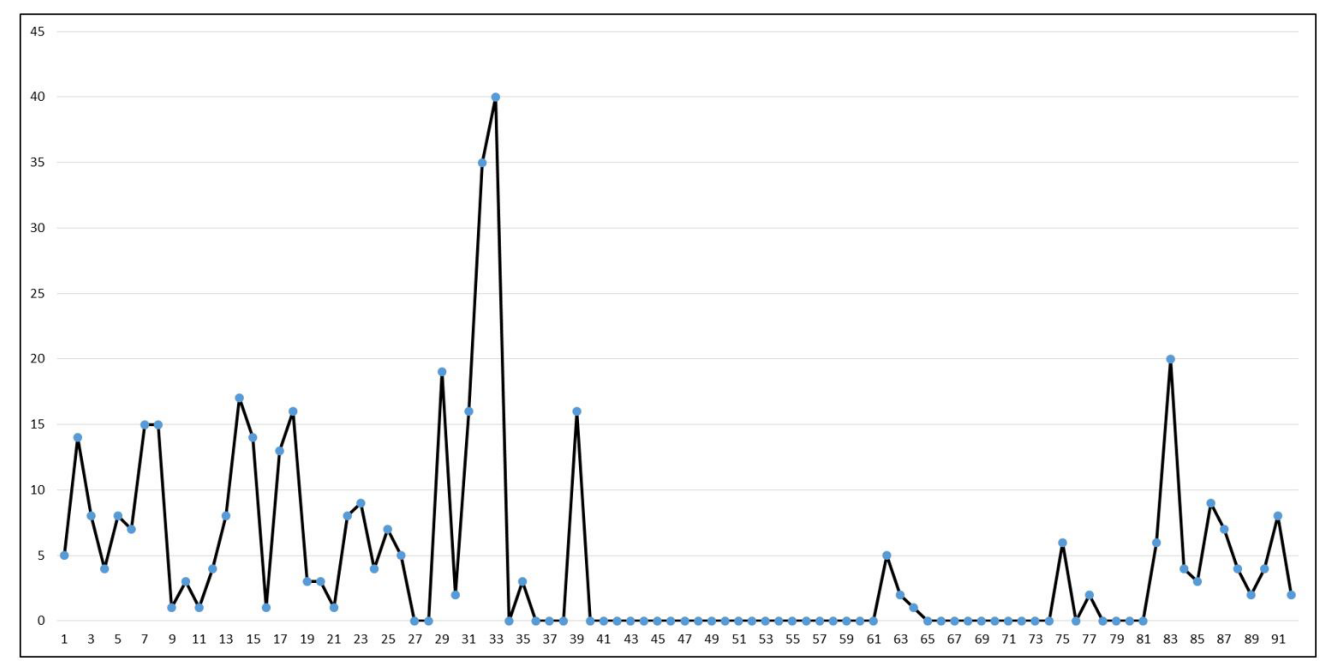

Figura 1. Empleo de usted en las cartas de Emilia Pardo Bazán

El gráfico ha de leerse teniendo en cuenta que de izquierda a derecha se contempla el número de cada carta, tal y como consta en la edición utilizada. De arriba abajo se ofrece la cantidad de ocasiones en que aparece el pronombre usted de forma explícita (siempre representado por una V. por la mano de Emilia, excepto en tres ocasiones, como ya se ha señalado). Lo relevante, entonces, no es la cantidad de veces en que aparezca el pronombre, dato que está íntimamente ligado con la longitud de cada epístola, sino el hecho en sí mismo de que aparezca de forma sistemática en una misma carta y, por tanto, esa carta en cuestión rechace el tuteo.

Como vemos, en la primera etapa siempre trata a Galdós de usted, como corresponde al protocolo y a la fase inicial de una mera relación discípula-maestro. En la segunda etapa, a partir de la carta 22 , hay a su vez una fase en la que sigue manteniendo el respeto implícito del pronombre usted, quizá por guardar las formas con respecto a terceros, quizá por seguir demostrándole su más sincero respeto, que se convierte en una clara familiaridad desde la epístola 40 hasta la 61 , en las que se atreve a tutearlo constantemente. Las últimas cartas de la que aún se puede considerar la segunda etapa son escritas respetando el pronombre de cortesía y distanciamiento (cartas 62-64), aunque vuelve de nuevo durante unas breves epístolas a retomar la antigua confianza del tuteo (cartas 65-74), justo antes de la tercera etapa que comenzaría con la epístola 64, para, finalmente, oscilar entre el usted (cartas 74-77) y el tú durante un tiempo (cartas 78-82) que termina, definitivamente, forzándola al uso del usted como marca de estricta amistad y recuerdo, tal vez, del respeto que nunca faltó (cartas 83-93).

Por último, cabe mencionar tres ejemplos en los que la escritora, sorprendentemente, utiliza el pronombre vos (en los dos primeros) y el de vuestra merced (en el tercero) para tratar a su lector, lo cual solo podemos explicarlo por la fuerte familiaridad, no exenta de chascarri1lo, que habría entre ellos, pues evidentemente en la práctica no era ya habitual el empleo de esos pronombres en español (Sáez Rivera 2014):

Escríbame V., escríbame V. aunque le cueste trabajo (material, se entiende). Si así lo hiciereis Dios os lo premie y si no os lo demande. (Carta 19)

¿Qué hacéis, pues, oh torquemadesco inventante? ¿Cuáles lusos os tienen así de la amistad divorciado? ¿Deberé ¡oh varón subterráneo y nebuloso! abrir oculta mina que a vuestra madriguera me conduzca embozada en el secreto? (Carta 86)

De todas suertes, en cuanto esté irá a las augustas manos de $V$. M. ratonil. (...) Se pintarán las decoraciones como V.M. disponga y se arreglará la escena a su gusto y descordojo. (...) Se necesita que V.M. me escriba una cartita oficial que pueda enseñar a los actores (...). (Carta 79)

Como hemos hecho con las cartas escritas por Rosalía de Castro, a continuación analizamos la forma en que Pardo Bazán se dirige a su interlocutor en las fórmulas de tratamiento, relacionadas con la dirección de la carta (\$3.2.1); en los vocativos que aparecen en el cuerpo del texto (\$3.2.2) y en el empleo de otros sintagmas que implícitamente están aludiendo a él (§3.2.3). 


\subsubsection{Dirección y saludo}

Durante la primera etapa de la relación (\$2.2), las maneras de dirigirse al lector son bastante protocolarias. De hecho, en las ocho primeras cartas (epístolas 2-9 de la edición empleada), además de en la decimosexta, decimoséptima y decimonovena, la autora escribe "Sr. Dn. Benito Pérez Galdós" en el encabezado del texto. En todas ellas excepto en la n ${ }^{\circ} 15$, que directamente comienza con una exclamación " $i Y$ vaya si le contesto pronto!", se muestra un saludo cortés: "Muy ilustre maestro y amigo" (carta 2), "Querido y respetado maestro" (carta 3), "Mi ilustre amigo" (carta 4), "Mi querido amigo" (cartas 5, 7, 13), "Ilustre amigo y maestro" (carta 6), "Amigo querido" (cartas 8, 9, 11, 19, 20), "Amigo Galdós" (carta 10), "Amigo mío" (cartas 12, 16, 18, 21) "Amigo querido e inolvidable" (carta 14), "Mi buen amigo" (carta 17).

En las cartas que componen la segunda etapa de la relación, el saludo empleado por la escritora es mucho más variado y creativo, como mostramos en la tabla 1, en la que hemos intentado organizar los sintagmas nominales en función del núcleo:
Como se ve en la tabla, la palabra más frecuente es "amigo", empleada en numerosas ocasiones, sobre todo, al principio de la etapa. Según va avanzando la correspondencia y se va profundizando en la relación, Emilia va ampliando su creatividad, como confirma el hecho de que hay expresiones que tan solo aparecen en una única ocasión.

Con respecto al segundo vocablo más utilizado, mico y sus derivados, hemos mantenido como sintagmas diferentes los que afectan a "bien" y a "miquiño" porque entendemos que el orden no tiene por qué ser equivalente. Así, "Mi bien, miquiño" (carta 51) otorga una primera fuerza al valor de la propia palabra bien como sustantivo, que queda explicado mediante la cariñosa aposición del diminutivo de mi$c o$. En la versión opuesta, "miquiño, mi bien" (carta 42), se emplea, a la inversa, el valor del sustantivo "bien" para reforzar el significado cariñoso del vocativo "miquiño".

A este respecto, por cierto, no nos atrevemos a decidir con total seguridad si el valor referencial de mico es el castellano 'mono' o el gallego 'gato'. Por un lado, puede entenderse el uso de miquiño como galleguismo, debido al

\begin{tabular}{|c|c|c|}
\hline Núcleo nominal & Sintagma completo & Cartas \\
\hline \multirow{4}{*}{ Adjetivos(s) + amigo } & Mi distinguido e ilustre amigo & 22 \\
\hline & [mi] ilustre amigo & $26,27,31,35,36,40,63$ \\
\hline & Ilustre y admirado amigo & 23 \\
\hline & mi querido e ilustre amigo & 25 \\
\hline amigo + doctor & Mi buen amigo e ilustre doctor & 24 \\
\hline Amigo + compañero & mi ilustre amigo y compañero de infortunios académicos & 32 \\
\hline \multirow{3}{*}{ Amigo + alma } & amigo de mi alma & 33 \\
\hline & amigo [mío] del alma & 28,30 \\
\hline & mi amigo & 29 \\
\hline \multirow{2}{*}{ ratón } & Mi ratón & 48 \\
\hline & [Mi] ratonciño [amado] & $38,45,46$ \\
\hline \multirow{4}{*}{ mico } & miquito amado & 41 \\
\hline & Miquiño & 52,56 \\
\hline & miquiño [mío] del [mi] alma & $43,44,54,55$ \\
\hline & miquiño, mi bien & 42 \\
\hline minino & minino & 57,62 \\
\hline cariño & cariño & 58 \\
\hline \multirow{3}{*}{ bien } & Mi dulce bien & 47 \\
\hline & bien & 59 \\
\hline & Mi bien, miquiño & 51 \\
\hline vida & Mi vida & 49 \\
\hline \multirow{2}{*}{ caro (it.) } & mi carino & 60 \\
\hline & carino, caro & 61 \\
\hline
\end{tabular}

Tabla 1. Principales saludos de Emilia a Benito en la segunda etapa de la correspondencia. Los corchetes indican las variantes 
morfema valorativo -iño que se junta a la posible raíz mico 'gato' (DRAG) y, además, al empleo de otro vocativo con valor similar como es "minino" (cartas 57 y 62). A este motivo cabría añadir el significado de 'ratoncita' que ella utiliza con cierta frecuencia para denominarse a sí misma (§3.4), lo que hace más próximo, entonces, mico a 'gato' que a 'mono'. Sin embargo, precisamente este sustantivo no registrado en lengua gallega pero sí en castellano, podría ser un argumento para defender el significado de 'mono de cola larga' (DLE) del término mico, debido también a la cantidad de ocasiones en las que la escritora se dirige al lector con vocativos como "mono" o "monín” (\$3.2.2).

En cualquiera de los casos, es probable que el punto de inflexión en la relación, tal y como se muestra en los saludos de las cartas analizadas, se encuentre en la número 37 , que comienza con "mi siempre amado", algo quizá ya demasiado alejado de la formalidad de las cartas anteriores, en las que prima el término algo más neutro "amigo". La carta 38 comienza con "mi ratonciño amado", mientras que la 39 muestra un "querido de mi corazón", todo lo cual, como vemos, marca un antes y un después en el trato lingüístico que ofrece al lector. De hecho, en la carta 46 ella misma parece mostrar que es plenamente consciente de dicha evolución: "Antes de que fueses mi amorcito, cuando solo eras mi amigo del alma y el hombre con quien charlaba más gustosa, ya ese viaje constituía para mí un hermoso sueño; ahora, figúrate".

Cabe igualmente mencionar otras cuestiones. Las cartas 60 y 61 son introducidas por italianismos porque, como dice la misma Pardo Bazán en la segunda epístola de las mencionadas, acaba de leer un texto en ese idioma y es probable que coincida con alguno de los viajes que él efectúa a Nápoles. Además de demostrar la cultura lingüística que posee, ella emplea dicha lengua probablemente también por las connotaciones socioculturales que implica: una lengua florida, amorosa, que se emplea fácilmente para conquistar sentimentalmente a las personas del sexo opuesto. No es de extrañar que la despedida de la sexagésima primera carta, de hecho, sea: "Te abrazo con toda la fuerza de mis brazos y de mi corazón, diletto, vita ed anima mia. Ti baccia caldamente, Porcia".

La carta 34 carece de introducción stricto sensu, ya que introduce el sintagma "amigo del alma" dentro de la primera oración: "Me llegó su carta de V., amigo del alma, en ocasión en que estaba leyendo a Luis Vives (...)", por lo que el vocativo puede entenderse como introducido plenamente en el cuerpo del texto. Algo similar sucede en las cartas 50 y 53, en las que no aparece ni dirección ni saludo alguno, pues los vocativos pueden ya interpretarse como plenamente introducidos en el cuerpo textual:

"Triste, muy triste"... como diría un orador de la mayoría, me quedé al separarme de ti, amado compañero, dulce vidiña. (Carta 50)

¿Conoces el papel? ¿Sí? Pues adelante. Ayer no te escribí, miquiño, porque aún dudaba la incertidumbre de las noticias y no sabía yo si me sería preciso marchar, lo cual en estos momentos (aparte de la causa) me sería perjudicial por encontrarme metida de cabeza en las pruebas de 2 tomos de crónicas de la Exposición. (Carta 53)

Por último, al final de la tercera etapa parece observarse una vuelta al trato de la etapa inicial, con algunas excepciones que resultan altamente sorprendentes debido a que muestran, a nuestro juicio, una extrema confianza entre ellos. Se trata de aquellos ejemplos en que la escritora utiliza personajes de las novelas galdosianas como sucede en la carta 82 con "Amiguito, señó Juan" y en la carta 83 con "Insigne Ldo. Del Sagrario" que, como constata Patiño Eirín (2013), es un error de transcripción de los editores por "Ido del Sagrario" (Tabla 2).

A esta tabla hay que añadir tres formas más, difíciles de clasificar mediante nuestra propuesta: "Amigo querido, inolvidable y escurridizo como una anguila" (carta 84), "Amigo, doctor, dueño, inolvidable y querido" (carta 86) y "Mi caro Venusino" (carta 87). La primera de ellas muestra la molestia que parece ella tener por la ausencia de sus cartas o, al menos, por el descenso en su frecuencia. En la segunda, Emilia Pardo Bazán está intentando hacerle ver, solo con el saludo, que tiene todos los méritos para ser admirado por ella: amistad ("amigo"), conocimiento ("doctor"), posesión ("dueño"), memoria ("inolvidable") y amor ("querido"). La tercera, finalmente, aplica el antropónimo de la ciudad de Venusia a Galdós, que es donde él parece encontrarse en el momento de leer la carta, como la propia Emilia explica unas líneas más abajo del saludo: "Los montañeses que ya conozco por aquí suponen a priori que no veré a Pereda, y también que no omitiré visitar su palacete de V. (Villa Venusina)". Evidentemente, no se puede descartar por completo el juego que el mismo adjetivo tiene como derivado del sustantivo Venus, diosa del amor en la mitología romana. 


\begin{tabular}{|c|c|c|}
\hline Núcleo nominal & Sintagma completo & Cartas \\
\hline \multirow{7}{*}{$\begin{array}{l}\operatorname{adjetivo}(\mathrm{s})+\operatorname{amigo} \\
\quad(+\operatorname{adjetivo}[\mathrm{s}])\end{array}$} & Amigo querido & 65 \\
\hline & [mi] querido amigo & 74,78 \\
\hline & Mi ilustre amigo & 76,89 \\
\hline & Mi admirado amigo & 90 \\
\hline & Mi ilustre y querido amigo & 91 \\
\hline & Amigo ilustre & 92 \\
\hline & Mi queridísimo y admirado amigo & 88 \\
\hline amigo + maestro & Querido amigo y maestro & 93 \\
\hline compañero & Mi querido compañero & 68 \\
\hline amigo + compañero & Amigo y compañero & 69 \\
\hline amigo + alma & Amigo querido del alma & 85 \\
\hline \multirow{5}{*}{ ratón } & Mi ratón querido & 70 \\
\hline & Mi ratón del alma & 79 \\
\hline & Ratonciño del alma & 66 \\
\hline & Ratonciño mío & 71 \\
\hline & Ratón campesino & 77 \\
\hline \multirow[b]{2}{*}{ roedor } & Amado roedor mío & 72 \\
\hline & $\begin{array}{c}\text { Caro roedor literario, inferior a los Urrechas como } \\
\text { embadurnador de costumbres }\end{array}$ & 73 \\
\hline mico & Miquiño mío & 75 \\
\hline cariño & cariño & 80 \\
\hline chico & Chiquito mío & 81 \\
\hline caro (it.) & carino & 67 \\
\hline
\end{tabular}

Tabla 2. Principales saludos de Emilia a Benito en la tercera etapa de la correspondencia.

Los corchetes indican las variantes

Observando la tabla en su conjunto, parece que también en esta ocasión lo más frecuente es el empleo del término "amigo" seguido de "ratón" y sus derivados, entre los que podemos incluir, por relación semántica, el término "roedor" (cartas 72 y 73), pues la metáfora constantemente empleada permite la referencia hiperónima al mismo animal. Cuando se emplea "amigo" con intenciones formales (cartas 84-93), la escritora vuelve de nuevo al uso del pronombre usted, aunque curiosamente no incluye la dirección oficial ("Sr. Dn. Benito Pérez Galdós") más que en algunas de esas epístolas $(88,90,93)$.

Resulta relevante resaltar la continuidad en la cariñosa animalización del interlocutor, si bien en esta última etapa se focaliza el valor en el concepto de ratón (cartas 66, 70, 71, $72,73,77,79)$ y se pierde prácticamente el de gato (valor gallego) o mono (valor castellano) que implica la palabra mico (carta 75), tan frecuente en la etapa anterior de la correspondencia. El motivo para proceder así puede deberse, simplemente, a una conceptualización del interlocutor que vuelve a las raíces profesionales que les unieron al principio, mucho más centradas en las lecturas, la literatura y, en general, todo lo que suponga el mundo de la cultura oculto por la imagen del ratón de biblioteca y, por tanto, del devorador de libros.

Este alejamiento que acaba conllevando la ruptura definitiva de la relación amorosa, aunque se mantenga la amistad, se plasma también en la recta final del epistolario, en la que ella le saluda retornando de nuevo al concepto de "amigo" que, como hemos indicado, se torna en el sustantivo más frecuente empleado por Emilia Pardo Bazán para referirse a Benito Pérez Galdós en sus cartas.

\subsubsection{Cuerpo del texto}

En el cuerpo de texto se refleja, en esencia, lo mismo que hemos visto en el saludo. Durante la primera fase, solo se registran vocativos relativamente formales como "maestro venerado" (carta 3), "maestro" (carta 18) y "amigo" (carta 15). 
A partir de la carta 22, sin embargo, los vocativos se hacen bastante más frecuentes, como intentamos sintetizar en la tabla 3.

A los expuestos en esta tabla, cabe añadir el vocativo "maestrillo" (carta 57), que ya había aparecido en su forma léxica original "maestro", tanto en el saludo (cartas 2, 3, 6, 64, 93) como en el cuerpo del texto (carta 18); y el de "pobrecito" (carta 59), que recuerda ligeramente a uno de los que emplea Rosalía de Castro para aludir a su esposo (§3.1). La utilización de
"Ganganelli mío" de la carta 53 puede explicarse, tal vez, como alusión al Papa Clemente XIV (Juan Vicente Ganganelli, en religión Lorenzo Ganganelli) o, simplemente, como fruto todo ello de la italianización que encontramos en algunas cartas pardobazanianas de la segunda etapa, como ya vimos anteriormente $(\$ 3.2 .1)$ con "Te abrazo con toda la fuerza de mis brazos y de mi corazón, diletto, vita ed anima mia. Ti baccia caldamente" (carta 61) y como igualmente atestigua "imbroglion di prima sfera" (carta 82).

\begin{tabular}{|c|c|c|}
\hline Núcleo nominal & Sintagma completo & Cartas \\
\hline \multirow{3}{*}{ Amigo } & Amigo del alma & 34 \\
\hline & Amigo querido & 34 \\
\hline & Mi amigo e inquilino eterno del consabido mío principal & 38 \\
\hline \multirow{3}{*}{ Mico } & Miquiño [adorado / amado] & $35,38,45,50,51,53,58$ \\
\hline & Miquito & 39,42 \\
\hline & mico & 43 \\
\hline \multirow{5}{*}{ Alma } & [Mi] alma [mía] & $35,53,55,56$ \\
\hline & [Mi] almita [amada] & $38,46,47,56$ \\
\hline & Pobre alma mía & 44 \\
\hline & Almita mía & 49 \\
\hline & Alma querida mía & 52 \\
\hline \multirow{2}{*}{ Facha } & Fachita & 35 \\
\hline & Fachiña amado & 38 \\
\hline Chico & Chiquillo & 35 \\
\hline \multirow{3}{*}{ Ratón } & Ratón & 35 \\
\hline & Ratonciño & 39 \\
\hline & Ratoncito [mío] & 54,60 \\
\hline \multirow{3}{*}{ vida } & [mi] vida [mía] & $38,39,50$ \\
\hline & vidita & 39 \\
\hline & [Dulce] vidiña [mona] & 50,56 \\
\hline niño & Niño & 38,58 \\
\hline \multirow{2}{*}{ mono } & Mono & $38,43,50,58,62$ \\
\hline & Monín & 41,43 \\
\hline pánfilo & Pánfilo de mi corazón & 43 \\
\hline arrastrado & arrastradiño & 45 \\
\hline mamarracho & Mamarracho mío & 46 \\
\hline nene & Nenito & 47 \\
\hline amado & Mi amado & 48 \\
\hline Bien & Mi bien & $48,50,51$ \\
\hline \multirow{2}{*}{ compañero } & Amado compañero & 50 \\
\hline & [mi] compañerito & 50,54 \\
\hline cielo & Cielo feo & 51 \\
\hline monigote & monigote & 51 \\
\hline corazón & Corazón & 51 \\
\hline felicidad & Felicidad mía & 50 \\
\hline bobo & bobito & 53 \\
\hline querido & querido & 54 \\
\hline
\end{tabular}

Tabla 3. Principales vocativos que Emilia Pardo Bazán dirige a su lector en el cuerpo del texto de las cartas entre 1888 y 1889 . Los corchetes indican las variantes 
Como se puede observar en la síntesis, esta segunda etapa se caracteriza por una creatividad algo mayor a la que hemos descrito con respecto al saludo, pues encontramos sintagmas nominales ausentes de él durante la misma etapa, como "chiquillo" (carta 35), "niño" (cartas 38, 58) y "nenito" (carta 47), que infantilizan al interlocutor, dotándolo de la característica de la juventud y la inocencia. Otros, como "pánfilo de mi corazón" (carta 43), "monigote" (carta 51), "arrastradiño" (carta 45) y "bobito" (carta 53) remarcan igualmente la ingenuidad del lector, como suele corresponder a las primeras etapas de la pasión amorosa. Esta idea de amor, por cierto, se deja entrever en los vocativos "corazón" (carta 51), "querido" (carta 54), "felicidad mía" (carta 50) y "mi amado" (carta 48), que contrastan, tal vez, con los iniciales "amigo del alma" (carta 34), "amigo querido" (carta 34), "Mi amigo e inquilino eterno del consabido mío principal" (carta 38) y los finales de la etapa "amado compañero" (carta 50) y "(mi) compañerito" (cartas 50, 54), todos ellos tal vez algo más neutros.

Los más frecuentes vocativos son los relacionados con los nombres mico (signifique 'mono' o 'gato') y alma, como sucede también en los saludos de la misma etapa, a los que siguen los derivados de vida, mono y ratón, que son menos frecuentes como tales. No cabe sorprenderse, entonces, de que el proceso de animalización siga teniendo lugar durante el cuerpo del texto, pues dentro de los cinco más frecuentes, como vemos, tres aluden a animales: mico, mono y ratón.

En efecto, igual que en el saludo, en el cuerpo del texto priman los vocativos derivados de "mico" (carta 43), como "miquito" $(39,42)$ y "miquiño" (cartas 35, 38, 45, 50, 51, 53, 58), seguidos de los derivados de "mono" (cartas 38, 43, 50, 58, 62), como "monín" (cartas 41, 43) y de "ratón" (carta 35), como "ratoncito" (carta 54 y 60) y "ratonciño" (cartas 39).

Como novedad con respecto a la forma de dirigirse a Benito Pérez Galdós en el saludo durante la segunda etapa de la relación, encontramos en el cuerpo del texto, por un lado, un curioso sintagma como "cielo feo" (carta 51); $y$, por otro lado, dos derivados del sustantivo facha, al que se le puede atribuir la segunda acepción que aparece en el DLE en la actualidad, 'Mamarracho, adefesio', precisamente porque la misma Emilia emplea en la carta 46 el sintagma "mamarracho mío" para referirse a él y, más adelante, ya en la tercera etapa, "grandísimo mamarracho dramático" (carta 82).
De forma similar a lo que ocurre con el valor semántico de "miquiño" (cartas 35, 38, 45, $50,51,53,58)$, cabe preguntarse si el diminutivo "nenito" (carta 47) proviene del castellano nene ('Niño de corta edad' [DLE]) o del gallego neno ('Persoa que está na nenez' [DRAG]), pues en ambos casos se alude a personas cuya edad se puede entender como comprendida entre el nacimiento y la adolescencia. Lo más probable, a nuestro humilde juicio, es que prime la interpretación castellana, dado que el DLE recoge en la quinta acepción de la palabra niño, equivalente, entonces, a nene, su uso como vocativo ('U. para dirigirse a una persona que ha pasado de la niñez'. U. m. en vocat.) y la misma escritora aplica el sufijo derivativo -ito siguiendo la norma castellana.

Por lo que respecta a la tercera etapa, la sucesión de vocativos dentro del cuerpo del texto es mucho más limitada que en la segunda, de la cual, sin embargo, se mantienen algunos como "mono" (cartas 67, 72, 79, 80), "alma mía" (carta 71) y "alma querida" (carta 75) y aparecen sintagmas nominales que no estaban en el cuerpo de texto de epístolas anteriores, como "cariño mío" (carta 70). Asimismo, la autora sigue siendo bastante creativa, sobre todo al principio de la etapa, como muestran "insulsote, tertuliano de la guantería" (carta 77), "tartáreo querub con la testa dolorida" (carta 78), "grandísimo mamarracho dramático" (carta 82) y el ya mencionado "torquemadesco inventante" (carta 86).

La inagotable pluma de Pardo Bazán, sin embargo, le permite incluso utilizar con fines amorosos adjetivos como "feo" (carta 79) y "feíño" (carta 80) que, en un contexto más neutro, pasarían por claramente negativos, aunque se encuentren ya en una etapa que denota más bien una desesperación unilateral por mantener algún tipo de relación.

Llama la atención, a este respecto, que en la carta 84 de nuevo se tope el lector actual con un error de transcripción, pues, como deja entrever Patiño Eirín (2013), los editores Parreño y Hernández escriben "Adiós, Yolito, insaissisable Proteo, hombre fugaz, como decía una poetisa de Padrón", cuando en realidad "Yolito" es "Idito", esto es, el conocido personaje galdosiano Ido del Sagrario. La poetisa a la que se refiere Pardo Bazán, por cierto, no es otra que Rosalía de Castro, naturalmente, quien en el poema "Un recuerdo" de La flor, escribe: "Yo escuchaba una voz... / ¡Era la voz de un hombre! / Sombra fugaz que se acercó liviana" (Patiño Eirín 2013: n. 4). 
Se repite, de este modo, en el cuerpo del texto un vocativo que ya veíamos como saludo en la sección anterior (§3.2.1): doña Emilia alude a don Benito nombrando a uno de sus más entrañables y emblemáticos personajes. Y, además, asoma en ella cierto grado de empatía por el sentimiento de ausencia que Rosalía tantas veces aplica a los hombres (Patiño Eirín 2013).

Siguiendo, por tanto, la evolución de los vocativos que se dirigen al interlocutor de forma directa y la manera en que plasman la relación entre los escritores, nos atreveríamos a indicar que conviene hacer una distinción entre el tratamiento que se da en el saludo, aunque creativo, más protocolario; y el tratamiento que se le da en el cuerpo del texto. Mientras que en el saludo, como dijimos, el punto de inflexión puede encontrarse en la trigésima séptima carta, en el cuerpo del texto, algo más libre que el saludo, como decimos, nosotros pondríamos ese punto de inflexión en la carta 34 .

No obstante, la importancia de la carta 37 no se puede subestimar, pues derrocha ejemplos de vocativos especialmente cariñosos, de los que carecen las cartas anteriores y posteriores.

\subsection{Nivel representacional (I): la percep- ción del yo en las cartas de Rosalía}

Hemos aludido anteriormente a la familiaridad que consta en el trato hacia Manuel Murguía en las cartas de Rosalía de Castro. Una forma más de atender a esta percepción del yo puede encontrarse en la manera en que introduce la firma $y$, posteriormente, en la manera en que efectúa dicha firma.

La introducción de la firma es lo suficientemente cercana como para que el lector entienda lo cotidianeidad del epistolario: "Tuya" (carta 2), "Un beso" (carta 5), "Recibe mi corazón" (carta 6), "Tu" (carta 7) y "Recibe cariños de todos y tú sabes te quiere tu mujer" (carta 8). De las cinco cartas de las que conservamos el cierre final, en dos de ellas aparece "Rosa" (cartas 2 y 7) y en tres consta "Rosalía" (cartas $5,6,8)$.

A este respecto, en la carta 6 , la edición de la Biblioteca Virtual Miguel de Cervantes, que sigue las ediciones de las obras completas de Manuel Arroyo Stephens y Mauro Armiño que a su vez, probablemente, siguen la edición de Juan Naya, se indica la firma "Rosalía" justificada a la derecha $y$, en la línea siguiente, justificado a la izquierda, se escribe "La niña, buena". Sin embargo, en el texto original que pone a disposición del internauta el Consello da Cultura Galega, se observa claramente que "la niña buena" no va separado por comas en ningún caso, que por ello precisamente constituye un sintagma nominal pleno y que funciona como una aposición por complementar al nombre propio "Rosalía". Es decir, "[o] que os primeiros transcritores tomaron como unha alusión aos desvelos da escritora pola saúde da súa filla, revélase agora como unha autonominación non exenta de ironía, en perfecta consonancia co carácter autoconsciente e lúdico da totalidade da escrita rosaliana", como se indica en los criterios de la edición realizada por Helena González Fernández, Maria Xesús Lama López y María do Cabreiro Rábade Villar.

Por otra parte, nótese que, por ejemplo en la séptima carta, el determinante posesivo indicado anteriormente para introducir la firma por encontrarse en una línea anterior a esta, "Tu", se completa evidentemente con el sustantivo "Rosa" y que, además, la estrecha relación entre ellos le permite a la escritora romper ligeramente el protocolo para escribir lo que se podría decir que es una despedida, seguida de una aclaración de la despedida ("Poca cosa") y, en sí misma, finalmente, la despedida en forma de firma ("Tu Rosa"):

Recibe toda mi alma y besos de tu pequeñita que quiere que le traigas una virgen vestida del sol y calzada de la luna. Poca cosa. Tu Rosa. (Carta 7)

En realidad, esta forma de escribir más creativa y libre que la exigida por situaciones formales (como veremos en las redactadas por Emilia Pardo Bazán), ya había aparecido en otras cartas:

Nada sabía de que Compañel estuviese enfermo. Cierto es que no tenía por quién. Apresúrate, sin embargo, a hacer cuentas; bueno será. Si yo fuese hombre, saldría en este momento y me dirigiría a un monte, pues el día está soberbio; tengo, sin embargo, que resignarme a permanecer encerrada en mi gran salón. Sea. Adiós. Recibe todo mi corazón y perdóname cuanto te hago sufrir: tú eres el que tienes que perdonarme a mí y no yo a ti. He leído ayer un cuento de Poe, precioso aunque sencillo. Allí comprenderías que era poeta. Otro que he leído de él, de un género opuesto, se parece al modo de escribir de Larra. Las damas verdes de Jorge Sand tienen muchísima semejanza en cierto estilo con mi joven azul. ¿Qué te parece? Van a decir que he querido imitarla. (Carta 2) 
En efecto, en este fragmento puede verse que hay una despedida clara ("Adiós. Recibe todo mi corazón") y que, sin embargo, a continuación sigue escribiéndole, como si de pronto recordara que no puede dejar de mencionarle el cuento de Poe leído anteriormente. Como decimos, esta estructura discursiva sería impensable si la relación entre ellos no fuera de estrecha familiaridad.

\subsection{Nivel representacional (II): la percep- ción del yo en las cartas de Emilia}

La percepción del yo puede observarse especialmente en dos lugares: la firma de las cartas y otros sintagmas nominales en los que la escritora alude a sí misma, especialmente en la línea justo previa a la misma firma.

En cuanto a las firmas, son bastante distintas a lo largo de la correspondencia, aunque nunca superan la diversidad que sí hemos observado en la manera de tratar al lector. Naturalmente, cuanto más formal es la carta, más formal es también la firma, especialmente en la primera etapa y en algunas misivas de la última. Recuérdese que la carta 22 es la primera de la segunda etapa, mientras que la carta 64 lo es de la tercera (§2.2): "Emilia Pardo Bazán" (cartas 2-5, 9, 12, 17, 22-24, 27, 31, 32, 35, 36, 40, 69, 76, 88-90), "Emilia P. Bazán" (cartas 6, 20, 25) "Emilia" (cartas 7, 8, 10, 11, 13, 14, 16, 18, 19, 21, 26, 63, 85, 91-93), "E." (cartas 15, 64), "[tu] Porcia" (cartas 45, 52, 56-58, 61, 65, 67, 68, 70, 71, 73, 77, 78, 80, 81, 84, 86, 87), "Doña Opas" (carta 46), "[tu] Peinetita" (carta 50) y otras formas como "Ratona" (66), "Matilde" (72, 74), "Paquita de Rímini” (82) y "Augusta" (79). En las cartas 86 y 87 matiza, respectivamente, "Porcia - infelix" y "Lydia - Porcia".

La despedida del resto de las cartas no lleva firma, lo que demuestra la extraordinaria cercanía que llegó a haber entre ellos: "Hasta luego, no olvido las señas. Haz por comer y no fumes mucho" (carta 28); "No me quieras mal, que te quiero mucho. Estoy muy triste" (carta 29); "¡Qué ganas tengo de verle! Hace un siglo. Un beso en la mano" (carta 30). Esta última epístola, por cierto, ejemplifica la ambigüedad de la relación que se da al principio de la segunda etapa, pues en ella emplea claramente el usted (como en tantas otras de dicha fase), pero evita la dirección "Sr. Dn. Benito Pérez Galdós" e incluye, sin embargo, el saludo "Amigo mío del alma".

La carta 33 concluye con un "Ojalá no haya jaqueca", símbolo de la familiaridad existente, igualmente, en otras epístolas que carecen de firma y recuerdan, en cierto modo, a las que Rosalía escribe a su esposo: "Gracias por tus bondades todas, y no me destierres al fin de ese corazón mío" (carta 37); "Envía el retratito, mono. Un beso por él” (carta 38); “(...) me hace falta un consuelito tuyo, Ratonciño, adiós (...)" (cartas 39, 60); "Te arranco el bigotito" (carta 43); "Hasta muy pronto" (carta 44); "En cuantique te vea te como" (carta 62).

En alguna ocasión, incluso, demuestra a las claras su amor por el lector, con despedidas como "Monín, adiós. Ya sabes que te quiero muchito. Hasta pasado mañana que te escribiré más largo" (carta 41); "Adiós mi amado, mi bien" (carta 48); "Te quiero con toda mi alma" (carta 49); "Te amo" (carta 51); "Te quiero, te quiero, te aguardo" (carta 53); "Hasta mañana, alma querida" (carta 75), así como cierto grado de celos, como se puede interpretar la última frase de la carta 47 ("Un beso, nuncio de otros") o las últimas líneas de la quincuagésima novena carta:

Este año se me figura a mí que he entrado en el período en que la vida no puede renovarse, y en que se mira atrás más que adelante, por imposición de la naturaleza. Pues bien: yo no quiero que me dejes. No: tú eres para mí. Para mí tus besos todos.

Hasta pronto que los haré efectivos (carta 59).

Tan solo en alguna ocasión esporádica surge la cuestión profesional de la que se ha hablado en la epístola: “¿Qué tal el versito? ¿Ni por esas me harán académica? Pues parece que Cheste fuera el alma" (carta 41).

En muchos de estos ejemplos puede observarse que ella desaparece del texto de una manera formal: al convertir la propia firma, la seña de identidad más clara de la autoría de un texto epistolar, en una llamada de atención hacia el interlocutor, enfatizada a través de numerosos vocativos como "mono", "monín" o "Ratonciño", la escritora parece estar diluyéndose en el tú y convirtiéndose, así, en alguien totalmente invisible, que es casualmente lo que se puede entender por la esencia del amor.

El caso de la trigésimo cuarta carta es interesante, pues se refiere a sí misma, al final, como "Su amiga que le quiere mucho, mucho, mucho", pero no incluye firma formalmente, lo que se muestra como una clara declaración de amor (o, al menos, de amistad y cariño), que ella sabe que el lector va a interpretar correctamente independientemente de que incluya su propio nombre. 
En el resto de las cartas, la alusión a sí misma justo antes de la firma sigue, más o menos, la línea mantenida en el trato al lector a lo largo de todo el epistolario, como mostramos en la tabla 3, clasificando las formas por etapas.

En efecto, lo primero que llama la atención es que la palabra "amiga" es la más frecuente durante todas las etapas, aunque es ligeramente más frecuente en la primera que en las demás. De hecho, en todas las cartas comprendidas entre 1883 y 1887 la frase previa a la firma siempre contiene el sustantivo "amiga", a excepción de la tercera carta, que alude a su condición de admiradora y discípula; y la decimoquinta misiva, que opta por un sintagma preposicional más directo para expresar sentimientos, como es "con todo el corazón".

En la segunda etapa ocurre algo similar, si bien en esta ocasión, además del sustantivo "amiga" complementado de diversas formas, como subordinadas de relativo ("que le quiere mucho, mucho, mucho", carta 33) o adjetivos de gran valor emotivo ("afectísima", carta 22; "verdadera", cartas 23, 31; "invariable", carta 34; "mejor y más leal", carta 26) se coordina con otros sustantivos como "admiradora" (carta 27), que aparece como núcleo en la carta 27; o es sustituido por nombres de personajes (cartas $46,50)$, que dejan entrever que la autora detecta que sus sentimientos van más allá de la simple amistad contenida en el término "amiga".

En la tercera etapa continúa esta autopercepción como pura "amiga" del interlocutor (cartas 64, 65, 69, 88-93), si bien se combina con un "soy tu siempre enamorada" (carta 71); "tuya" (cartas 72, 79); "suya" (78), "de V." (86) y, tal vez el más llamativo, un "toma un beso de tu disgustada" (carta 66).

\begin{tabular}{|c|c|c|}
\hline $1^{\mathrm{a}}$ etapa & $2^{\mathrm{a}}$ etapa & $3^{\text {a }}$ etapa \\
\hline $\begin{array}{l}\text { Reciba V. una vez más el testimonio } \\
\text { del afecto y respeto que le profesa su } \\
\text { amiga qbsm (2) }\end{array}$ & Su amiga afectísima (22) & Su amiga $(64,74)$ \\
\hline $\begin{array}{c}\text { Así pudiese hacerlo su admiradora y } \\
\text { leal discípula qbsm (3) }\end{array}$ & Su muy verdadera amiga q.b.s.m. (23) & Su verdadera amiga (65) \\
\hline $\begin{array}{l}\text { Siempre su respetuosa amiga y } \\
\text { admiradora - Q b s m (4) }\end{array}$ & Su amiga y admiradora invariable, qbsm & Toma un beso de tu disgustada (66) \\
\hline Su amiga verdadera (5) & Créame su mejor y más leal amiga (26) & $\begin{array}{c}\text { Téngame por su verdadera amiga y } \\
\text { admiradora (69) }\end{array}$ \\
\hline Le quiere muy de veras su amiga (6) & Le saluda cariñosamente su admiradora (27) & Soy tu siempre enamorada (71) \\
\hline $\begin{array}{c}\text { Dé la gran satisfacción de hospedarle a } \\
\text { su amiga (7) }\end{array}$ & Un beso en la mano (30) & Tuya $(72,79)$ \\
\hline $\begin{array}{l}\text { Su amiga que le saluda de parte de todos } \\
\text { y siente mucho no verle pronto (8) }\end{array}$ & Su amiga verdadera (31) & Suya (78). De V. (86) \\
\hline $\begin{array}{l}\text { Acuérdese alguna vez de su más leal } \\
\text { amiga - q b s m (9) }\end{array}$ & $\begin{array}{l}\text { Siempre amiga de V. a despecho de } \\
\text { cabeceras y cabecillas }(32)\end{array}$ & $\begin{array}{l}\text { Ya sabe V. que de todos modos le } \\
\text { quiere mucho y no le admira } \\
\text { menos (87) }\end{array}$ \\
\hline Mande a su amiga (10) & $\begin{array}{l}\text { Su amiga que le quiere mucho, mucho, } \\
\text { mucho (33) }\end{array}$ & Su invariable amiga $(88,93)$ \\
\hline Su amiga que desea verle (11) & $\begin{array}{l}\text { Se lo agradecerá muy de veras su } \\
\text { invariable amiga y admiradora q b s m (34) }\end{array}$ & $\begin{array}{l}\text { De V. como siempre cariñosa y } \\
\text { verdadera amiga (89) }\end{array}$ \\
\hline Su amiga $(12,14,16)$ & $\begin{array}{c}\text { su siempre amiga y admiradora entusiasta } \\
\text { q. b. s. m. (35) }\end{array}$ & De V. siempre verdadera amiga (90) \\
\hline Su amiguísima (13) & $\begin{array}{l}\text {...soy de V. amiga, admiradora y } \\
\text { compañera qbsm (40) }\end{array}$ & Siempre su mejor amiga (91) \\
\hline Con todo el corazón (15) & $\begin{array}{l}\text { Un besito de tu doña Opas que no puede } \\
\text { más y lo lamenta muy de veras (46) }\end{array}$ & $\begin{array}{c}\text { Su siempre constante y vieja amiga } \\
(92)\end{array}$ \\
\hline Su amiga verdadera (17) & $\begin{array}{l}\text { Peinetita, que te besa un millón de veces el } \\
\text { pelo, los ojos, la boca y el pescuezo (50) }\end{array}$ & \\
\hline Suya (21) & Su invariable admiradora (63) & \\
\hline
\end{tabular}

Tabla 4. Autodenominaciones de la escritora en las líneas anteriores a la firma. Entre paréntesis se indica el número de la carta a la que pertenece el ejemplo 
Como puede observarse, independientemente de la etapa, en todos los casos en que firma como "su amiga" hay un tratamiento de usted, lo que implica una ausencia formal (y aparente) de confianza. No es, entonces, casualidad, que en algunas cartas no se despida aludiendo a sí misma, sino simplemente empleando una frase que hace referencia al lector $o$ al deseo de volver a verle. Normalmente, esta forma de despedirse coincide con la ausencia de una firma explícita, sea coloquial como "Porcia", sea formal como "Emilia Pardo Bazán" y tiene lugar tanto al final de la primera etapa, como durante la segunda y a principios de la tercera: "Y ahora, al amigo... ique me escriba!" (carta 18); "Monín, adiós. Ya sabes que te quiero muchito. Hasta pasado mañana que te escribiré más largo" (carta 41); "Te quiero con toda mi alma" (carta 49); "Hasta mañana, alma querida" (carta 75).

Por lo que respecta a los sintagmas nominales que permiten definirse a sí misma, cabe resaltar algunos que han llamado nuestra atención. Así, en la carta 129 se llama "princesa galaica" y en la 43 alude a "mi condición de gallega arrulladora y mimosa". En efecto, esta idea es la que en ocasiones puede transmitir al lector de ella misma: la de una mujer fuerte y a la vez frágil, noble por aristócrata, de origen evidentemente gallego, que lucha con todas sus fuerzas por mantener el amor del hombre del que está aparentemente enamorada. Ella parece ser plenamente consciente de que él le permite este comportamiento, como explica un par de líneas más arriba de lo citado, dentro de la misma carta 43: "Por lo demás, y autorizada y rogada por ti, lo fácil y agradable para mí es hacerte mil zalamerías".

En dicha epístola, un par de párrafos más abajo, ella misma insiste en bailarle el agua en busca, probablemente, de su perdón tras el engaño, alabando todas sus virtudes literarias y calificándose a sí misma como una de las más fieles seguidoras de su trabajo (y de su persona):

Tengo ganas de conocer esos planes literarios y de ver ese arrastrado drama en pruebas, cuartillas o como tú permitas a esta tu admirada y apasionada (en todo el rigor de la frase).

Doña Emilia no puede quedarse fuera del proceso de animalización que efectúa sobre él, por lo que no cabe sorprenderse en demasía de que se considere a sí misma una "rata", como pareja del "ratonciño" que tantas veces emplea para referirse a Galdós (§3.1): "Ratonciño: $t u$ rata está aquí, en el Hotel Central" (carta 45), "soy tu rata que te ama" (carta 49). Siguiendo con el proceso de animalización, ella es también una "buitra esperando por su pájaro bobo, por su mochuelo" (carta 55) y, de forma algo menos agresiva sexual (y semánticamente), también se considera "borriquita": "Te quiero mucho, mucho, pero hoy no te lo puede decir bien tu Borriquita" (carta 55).

Finalmente, cabe señalar un fragmento en el que ella se trata de usted a sí misma, en un afán por convencerse de llevar un estilo de vida apropiado a su género, cuando está deseando vivir de forma contemplativa:

La cuestión de aurículas y ventrículos no sé cómo resolverla. (...) algunas veces (...) se me ocurren unas filosofías raras y estrambóticas que se resuelven en esto (...): cortarme los dos ventrículos y las dos aurículas y entregarme solo al arte y a la meditación y al estudio, porque además me parezco vieja ya para tanta hipertrofia del corazón... Pero el sentido común me dice: cuidadito: V. es así... un poco sulfúrica... y si a lo mejor se mete $V$. en una temporada de elevación mental... ni el Bajísimo la sufre a $V$. después cuando venga la reacción inevitable. (Carta 58)

Vemos, por tanto, que la visión que ella tiene de sí misma es clara y firme en la primera etapa y al final de la última, pues mientras el amor dura, aunque sea de forma más unilateral, es decir, ya desde principios de la tercera fase, ella deja diluir su propia identidad en el nombre del lector que es, naturalmente, su amado amante. Cuando ya se va desdibujando su relación amorosa y poco a poco vuelve a convertirse de nuevo en una sincera amistad, la escritora vuelve a verse como ella misma, enfatizando la relación entre ellos pero sin perder su propia identidad.

\subsection{Nivel morfosintáctico (I): la modalidad subjetiva en las cartas de Rosalía}

De los ejemplos encontrados con perífrasis verbales en primera persona del singular dos indican, de forma bastante pesimista, la obligación externa natural que concibe la acción denotada por el infinitivo morir como tristemente inevitable:

Pero dejemos de hablar de esto, puesto que, según todas las trazas, sea hoy, sea mañana, más tarde o más temprano, pienso que tendré que morir despacio y a modito, y sin duda será un bien, porque en realidad me hallo cada vez menos resignada, y por lo mismo menos a bien 
con Dios; y de este modo, muriendo de repente me iría muy mal. (Carta 3)

Gallinas no quiero comprar más; lo mismo me he de morir de un modo que de otro. (Carta 3)

La perífrasis tener que + infinitivo, en el siguiente ejemplo, no obstante, expresa la obligación externa social que se genera por unas circunstancias convencionalmente acordadas, de las que ella, en este caso como mujer, no puede escapar:

Si yo fuese hombre, saldría en este momento y me dirigiría a un monte, pues el día está soberbio; tengo, sin embargo, que resignarme a permanecer encerrada en mi gran salón. (Carta 2)

Los dos ejemplos con poder + infinitivo expresan posibilidad epistémica y permiso, en el caso de la cuarta carta; y prohibición externa natural, en la quinta carta. Así, la posibilidad epistémica se produce si reducimos la interpretación a una mera opinión, mientras que el permiso puede ser tanto social como natural: es social, si atendemos a un significado más centrado en la capacidad que le otorgan las circunstancias de extraer miseria de todo lo que le ha ocurrido recientemente; es natural, si defendemos que ella se siente perfectamente capaz (facultativamente capaz) de extraer la miseria en que es capaz de convertir lo que sucede a su alrededor. El poder + infinitivo de la quinta carta expresa la prohibición externa natural, debida a las propias limitaciones del ojo humano:

No obstante, cuando reflexiono en la miseria que puedo sacar de todo me dan ganas de hacer trizas cuentos, novelas y aun mi loca cabeza, que tiene la manía de entretenerse en tales cosas. (Carta 4)

Me ha gustado muchísimo el rostro, y una Virgen de los Dolores que hay allí, también me pareció buena, aunque era ya algo noche y no la pude ver bien. (Carta 5)

En síntesis, por tanto, las perífrasis verbales no factuales en primera persona del singular en las cartas de Rosalía de Castro expresan una concepción de la modalidad subjetiva centrada en la obligación y la contra-obligación o prohibición, en ambos casos, externa, lo que da una idea de la posible opresión que podía sentir la escritora al narrar, para su esposo, la relación de sus más profundos sentimientos con la realidad cotidiana.

\subsection{Nivel morfosintáctico (II): la modalidad subjetiva en las cartas de Emilia}

Para poder aproximarnos a la expresión de la modalidad subjetiva de Pardo Bazán, podemos aplicar la taxonomía utilizada en otros trabajos (Fernández Martín 2014, 2015), basada en la distinción entre una considerable diversidad de modalidades deónticas (e, implícitamente, epistémica y facultativa): la obligación, que será externa (natural o social) o interna (moral); la prohibición o contra-obligación, que igualmente puede ser externa (natural o social) o interna (moral); dentro de la no-obligación, se encontrarían la exención o no necesidad, la necesidad, el permiso, tanto social como natural (o facultativo, ausente de nuestro corpus); y la posibilidad epistémica, que aporta una evaluación sobre las condiciones en que se da la verdad del predicado (Ridruejo 1999).

Así, los siguientes ejemplos muestran la obligación externa natural porque el agente no tiene libertad de elección, como muestra el valor semántico del infinitivo al que complementan: ¿hasta qué punto puede alguien libremente obligarse a sí misma a realizar las acciones de los verbos mentis como "creer" en alguien o "reconocer la verdad de los hechos" o, incluso, a sentir, como muestra el verbo "querer"?

(...) he perdido un amigo en quien creía porque debía creer (hablo de Daniel). (Carta 30)

(...) pero también yo he de reconocer la verdad de los hechos (...). (Carta 42)

Mi compañerito, querido, tú bien sabes - porque lo sabes todo- que yo tengo que quererte mucho (...). (Carta 54)

Similarmente, la obligación externa social, que hemos registrado en una veintena de casos, aparece cuando las circunstancias fuerzan a la realización de la acción, de manera que la capacidad de elección del agente es bastante reducida, si bien no es completamente inexistente como sucede con la obligación externa natural:

Será cosa breve, y cuento con que en todo el mes de Julio la he de despachar. (Carta 15)

Basta de desatinos. ¿V. viene, u no? ¿He de asistir a ese ensayo (...) u no? (Carta 86)

Al expresar esta obligación con haber de + infinitivo, nuevamente se deja entrever el valor de futuro, al que se añade el de necesidad cuando la perífrasis es tener que + infinitivo: 
¿Sabe V. que tengo que pedirle (...) que envíe un ejemplar a cierto crítico italiano muy diligente y diestro que se interesa mucho por el movimiento novelesco español? (Carta 9)

¡Y que además tengo que pedirle un favor! (Carta 10$)$

(...) siempre resultaba que tenía yo que ir a comer con algún renglón de la Guía de Forasteros, cuando apenas acababa V. de llegar a mis dominios (...). (Carta 15)

Si no fuese el maquiavelismo y las precauciones, acaso podrías asociar la administración de mis libros a la de los tuyos, pues yo soy literalmente incapaz de administrarme y siempre tendré que estar a merced de los editores (...). (Carta 39)

Si en lugar de valor de futuro o de necesidad, el que prima en la expresión de la obligación externa social es el condicional, es decir, el hacer depender la realización de la acción denotada por el infinitivo de un hecho concreto y completamente ajeno a la voluntad del hablante (que ocurra una desgracia, que su madre se decida, que el lector no experimenta necesidad de escribir a Emilia de forma íntima), entonces la perífrasis empleada es deber + infinitivo:

Mi único interés es que no ocurra una desgracia y que no se me ponga entre ceja y ceja que debo irme a las Américas a estudiar los pastos. (Carta 42)

(...) porque como mamá se propone ir conmigo (...) debo esperar hasta que ella se decida. (Carta 57)

(...) pero como he visto que $V$., desde hace algún tiempo, no experimenta o no parece experimentar necesidad de esa íntima comunicación, he creído que debía ajustarme a su orden de sentimientos y no exhibir el mío (...). (Carta 84)

Menos frecuente es, en las cartas analizadas, la expresión de la obligación interna, patente en apenas una decena de casos, cuando la acción denotada por el infinitivo es entendida como deber propio, como demuestra el hecho de que se trata de decisiones asumidas por ella misma en el ejercicio de su plena voluntad:

Por todas estas razones, tu línea de puntos suspensivos es, en ocasión como la presente, un poquillo cruel: reconozco sin embargo el origen de que procese, y no solo debo comprenderla sino justificarla. (Carta 61)

Yo sí que debía renunciar a la lectura y deletrearte a ti solo. (Carta 51)

En el siguiente ejemplo, la obligación expresada por deber + infinitivo es claramente interna $\mathrm{y}$, por tanto, moral, pero a la vez solo es posible llegar a ella desde una forzada situación muy concreta que pueden convertir la obligación asumida como propia en una obligación externa social:

Me he propuesto vivir exclusivamente del trabajo literario, sin recibir nada de mis padres, puesto que si me emancipo en cierto modo de la tutela paterna, debo justificar mi emancipación no siendo en nada dependiente (...). (Carta 38)

En efecto, resulta altamente complejo distinguir la obligación interna expresada por deber + infinitivo, de la obligación interna expresada por haber de + infinitivo, pues con esta segunda perífrasis verbal se acompaña un matiz de circunstancias inevitables que llevan a tomar la decisión seleccionada y que, por esto mismo, no exenta tampoco de valor temporal de futuro:

En suma, he de ser yo misma quien me emancipe (...). (Carta 39)

Si me quedo (que lo dudo) ya no tienes más que fijarme el día en que he de acudir a Maravillas Church, Palma Alta Strasse, a las 6 en punto. (Carta 55)

$\mathrm{Al}$ agradecer su pésame, he de dar a V. otro, que ya fui a ofrecerle en persona. (Carta 93)

Una rama específica de la obligación interna, llamativamente expresada por la perífrasis po$d e r+$ infinitivo en afirmativo (pues si estuviera negada por un adverbio como no o nunca, no sería extraño que expresara la contra-obligación o prohibición), la encontramos en los casos en que el infinitivo es un verbo de lengua: "puedo asegurarte" (carta 71); "lo que puedo asegurar" (carta 84); "puedo decir" (cartas 53 y 84); "puedo sin mentir decir" (carta 54). En estos ejemplos, ella asume un compromiso pleno con sus propias palabras, pues equivalen, pleonásticamente, a "aseguro" y "digo", lo que la ata a ellas forzosamente sin dejar espacio a la posibilidad epistémica, a la necesidad o a la exención.

Nótese la diferencia con otros casos con el mismo verbo de lengua decir o con uno similar como escribir, en los que el valor existente se acerca más a un permiso social (que supera la decena en las cartas de Emilia Pardo Bazán) que a una obligación. En el primer caso, el hecho de que pueda decir poco sobre la vida literaria está condicionado a las circunstancias que han evitado que, hasta la fecha, se haya familiarizado con ella. En los dos siguientes 
ejemplos con escribir, son igualmente las mismas circunstancias socioculturales las que permiten entender que ella tiene la posibilidad de escribir:

De la vida literaria por acá poco puedo decir aún, pues es el segundo año que vengo (...). (Carta 6)

Hoy es domingo, llueve, nada me apremia: puedo escribir a mi gusto. (Carta 84)

Amigo querido: pasado el 12 me dice V. que le escriba a Madrid; llegó el 14, estoy pues en regla, y puedo escribir. (Carta 19)

La imposibilidad de comprenderlo como permiso natural se encuentra en que todo ser humano con una mano y un cerebro, por así decirlo, puede de forma natural escribir, si bien las circunstancias sociales son las que facilitan (permiso social) que esta capacidad se convierta en un hecho. En cambio, cuando efectivamente llega una circunstancia que no se puede controlar, por escaparse del rigor de lo puramente social, la imposibilidad pasa a ser plenamente natural, en cuyo caso deja de darse el permiso para darse la prohibición externa (natural). En el siguiente ejemplo, esto se muestra con el mismo verbo escribir, de cuya acción Emilia se siente incapaz debido a la colerina:

Pero después vino otro mal, la colerina, que he tenido con sus síntomas todos y me ha dejado tan débil que apenas puedo escribir. (Carta 70)

En el mismo contexto en que refiere la muerte de su padre, ella se expresa entre el permiso social, dadas las circunstancias ajenas en las que se encuentra, y el natural, debido a lo imposible de controlar el tiempo y su propio estado de ánimo:

Carino, me voy hoy mismo, a escape, llamada por tristes y apremiantes telegramas, que te enseñaré a las $31 / 2$, la única hora de que puedo disponer, en el asilo. (Carta 67)

No deje V. de escribirme, pues sus cartas serán de las pocas que hoy puedo desear recibir. (Carta 69)

El permiso social, por tanto, se encuentra a caballo entre la posibilidad epistémica y la no obligación en general:

(...) porque el jueves es cuando puedo tener lo más pronto respuesta acerca del asunto. (Carta 55)
Dime si en el $\mathrm{n}^{\circ}$ de Enero puedo hablar de eso ya del Teatro puedo hablar de eso ya y lanzar la cosa como se debe, en toda regla, con su "Boca abajo todo el mundo" correspondiente. (Carta 80)

En cambio, solo hemos registrado un caso de pura necesidad (el primero del siguiente grupo) y tres de permiso natural o capacidad facultativa (los demás):

El Director del periódico bonaerense me telegrafía aceptando mis proposiciones, por lo cual a poco de llegar ahí tendré que dar una vueltecita por París. (Carta 42)

Mi ilustre amigo: ya sabe $\mathrm{V}$. que yo conozco sus urgentes y gloriosas tareas y puedo explicarme perfectamente su retraso en escribir. (Carta 4)

Entonces pude cerciorarme de que ese amor moderno, nervioso y hasta con sus ribetes idealistas (...) lo tenías tú por esta princesa galaica. (Carta 129)

Lo que te amo te basta, mira que yo en un minuto te puedo dar más bienes y más alegrías que nadie; sobre todo, a mí es a quien quieres; no lo olvides. (Carta 37)

La posibilidad epistémica, que igualmente ronda la decena, aparece con claridad cuando la perífrasis poder + infinitivo depende sintácticamente de un verbo de opinión:

En tanto lo que sus propósitos me han agradado, que si creyese que podía contribuir al éxito pondría al frente mi nombre como directora (...). (Carta 24)

Pero (...) no veo qué genero de apoyo podría encontrar en ti. (Carta 39)

Jamás he comprendido que pudiese yo estar enamorada y mal correspondida. (Carta 39)

En otras ocasiones, la interpretación epistémica se encuentra en la posibilidad de que la escritora asuma la acción denotada por el infinitivo como una mera opción, por lo que se convierte, por así decirlo, en una opinión sobre un hecho posible, tan solo registrada en una ocasión con deber de + infinitivo:

Estos días debo de haber ganado lo menos una banasta de roscas, porque hice un trabajo para la Fortnightly Review sobre "Las mujeres españolas" (...). (Carta 41)

(...) conste solo que me duele mucho haber podido darte un mal rato involuntariamente. (Carta 47) 
Como expresión antónima de la obligación externa natural y del permiso natural, la contraobligación o prohibición externa natural es bastante frecuente en las cartas analizadas:

(...) hay una identificación extraña del cariño anterior a nuestra amistad íntima, de esta amistad, y de la nostalgia que siempre me produjo y producirá su falta, y al enlace de estos sentimientos no puedo darle nombre (...). (Carta 84)

No he podido comer: es cuanto cabe decir a V. (Carta 33)

No puedo explicarte este estado moral. (Carta 38)

No he podido acabar esta carta ayer, ni hoy por la mañana. ¡No saldrá el martes, y tú tendrás el jueves una rabieta! (Carta 58)

Más frecuentes son, sin embargo, los ejemplos que expresan prohibición externa social, alrededor de la veintena, pues en todos estos casos la hablante está plenamente atada a las circunstancias, que son las que evitan la posibilidad de realizar la acción denotada por los respectivos infinitivos:

¡Cuánto partido hubiera V. sacado, a fuer de observador, de mi viaje a Celanova, cuya más más divertida parte no puedo yo referir a los suscritores del Imparcial! (Carta 18)

La mía, fechada el 13, no pude echarla hasta el 16. (Carta 34)

Esta gente se me embelesa aquí y no la podré arrancar antes del Viernes, día 4 (...). (Carta 47)

Pero ahora ya no sé, y por consiguiente, no puedo decirte: así es que la seña de mi llegada (dado que no puedo telegrafiarte tampoco) será la idea de Jaime a tu casa. (Carta 49)

Finalmente, apenas hemos encontrado unos pocos casos que implican una prohibición interna, es decir, la obligación de no realizar una acción que el propio hablante se fuerza a sí mismo a cumplir:

Solo que (esa idea) no puedo admitirla enteramente. (Carta 42)

Pero como yo no había de admitir sino el precio de mi trabajo, en concepto de colaboradora, y en otro concepto las delicadezas y obsequios que prescribe la galantería tratándose de una mujer, y nada más, de ahí que toda esta cuestión de Revista sea aparte de la de mi emancipación y no tenga nada que ver con ella. (Carta 39)

No haga V. uso alguno de esto que le digo; reserve, observe, y tome nota, que yo tampoco he de proceder de otra manera. No pienso decirle nada [a Daniel], o casi nada. (Carta 33)

Por otra parte, dado que la primera persona del plural incluye, necesariamente, al emisor, creemos conveniente también añadir al análisis algunos casos en que el sujeto es "nosotros", pues en estas ocasiones la escritora se está refiriendo tanto a ella misma como a su lector. Parece que cuando emplea la perífrasis poder + infinitivo se pretende expresar la posibilidad epistémica que se oculta tras toda opinión, pero naturalmente el permiso natural (capacidad facultativa) y el permiso social (mientras se guarden las formas) ocultan una clara sugerencia pragmática no poco cargada de planes de futuro en común:

Solo tú y yo podemos comprender hasta qué punto es disculpable y hasta loable este modo de sentir nuestro (...). (Carta 42)

No hemos hecho más que arrimar la manzana a los dientes, éstas es la verdad, no hemos agotado, ni siquiera bebido a boca llena el dulce licorcito que nos podemos escanciar el uno al otro. (Carta 53)

Nosotros (y tú especialmente) podemos decir aquello de "no moriré todo aunque muera". (Carta 71)

Al emplear la perífrasis haber de + infinitivo, se refuerza la carga semántica de posible proposición, que pasa a convertirse en una obligación externa natural, en la que se concibe como inevitable la acción denotada por el infinitivo:

En tu carta me señalarás el sitio en que hemos de vernos, sea en el asilo, sea en Palma-Strasse. (Carta 59)

Hemos de ir a Oriente tú y yo, ni más ni menos que Matilde y Alek-Adel. (Carta 71)

En estos ejemplos (tal vez más con los que contienen haber de + infinitivo que con los que tienen poder + infinitivo) da la sensación de que la escritora no quiere que el lector se escape de sus garras de "buitra" (carta 54): al hablar de "nosotros" la unión entre ellos se confirma lingüísticamente, lo que obliga al interlocutor a configurar un sujeto posible junto a ella misma, a realizar juntos la misma acción en un futuro cargado de irrevocabilidad. El posible flirteo que permite poder + infinitivo, a caballo entre la complicidad de la opinión común y la capacidad de realizar acciones que permiten ser negadas, no lo acepta haber de + infinitivo, que ofrece una obligación sin réplica, unos 
planes de futuro en común que no pueden, bajo ningún concepto, dejar de realizarse.

En resumen, pues, el hecho de que los dos valores más frecuentes se relacionen con lo social, tanto la obligación externa como la prohibición externa, nos permite deducir que la voluntad de Emilia Pardo Bazán es lo suficientemente fuerte como para realizar aquello que se proponga, teniendo en cuenta las circunstancias lógicamente sociales y, por tanto, evitables (y también las naturales, es decir, inevitables) que en cada caso la rodean. Un ejemplo de esta fortaleza se encuentra, como es sabido, en la intención de emanciparse de los ingresos paternos una vez que, seguramente no sin dudas, así lo decide.

\section{Interrelación entre las cartas de las dos es- critoras}

Antes de efectuar las comparaciones que deseamos, cabe aludir de nuevo a la enorme diferencia cuantitativa que ya hemos señalado en los respectivos corpus epistolares. Esta alusión nos parece relevante porque es seguramente fruto de la misma diferencia de clase que encontramos entre la condesa de Pardo-Bazán y la hidalga De Castro. Es posible preguntarse, por ejemplo, qué habría ocurrido si Rosalía de Castro hubiera pertenecido a una familia con poder y no hubiera tenido, quizá, tanto temor a que supuestamente su imagen social (en el sentido de face) se perjudicara por medio de sus cartas. O, en otras palabras, cabe plantear, simplemente, hasta qué punto depende de los recursos socioeconómicos una decisión de tal calibre en dos personajes que comparten género, origen geográfico y prácticamente época.

El trato al interlocutor que observamos en las cartas es, sin embargo, muy diferente (nivel interpersonal). Rosalía siempre tutea a Manuel, pero lo hace desde la familiaridad que da el cariño, la comprensión, la confianza y el trato constante. Emilia tutea a Benito solo durante una época muy concreta (desde abril de 1889 hasta finales de 1891), interrumpida por algunas cartas en las que le trata de usted, probablemente para guardar las formas. A nuestro juicio, este tuteo se relaciona más directamente con la confianza típica de la pasión amorosa que supone la entrega mutua, que con el cariño que se desprende del contacto diario que, además, sería esencial y profundamente epistolar, a diferencia de la relación De Castro-Murguía, que se habría forjado alrededor del contacto físico y el roce continuo.
Asimismo, en la época en la que ambas relaciones son más comparables, la coruñesa idealiza a su interlocutor en un afán por caerle en una gracia al principio solo intelectual, al denominarlo con distintos nombres de personajes de las propias novelas galdosianas como el entrañable Ido del Sagrario, que va cambiando con su creador por el paso de El doctor Centeno, Lo prohibido, Tormento y Fortunata y Jacinta (Gallego Roca 2015).

Esta idealización se plasma también en el constante proceso de positiva animalización (como muestran los frecuentes diminutivos, sea en -iño, sea en -ito) que opera en la inmensa mayoría de las cartas, bien en el propio saludo, bien en el cuerpo del texto (nivel representacional).

Los sustantivos que denotan animales más frecuentes, como vimos, son los de mico, mono y ratón. Así, suponiendo que mico signifique 'gato', puede entenderse aquí como un rasgo de dulzura, como corresponde a un animal que es muy independiente pero siempre está buscando el contacto humano. El mono, por su parte, se muestra como un animal gracioso, inquieto, ágil, bromista y más similar al humano que cualquier otro ser, debido a su inteligencia y a su consciencia del otro. El ratón, visto como un animalillo indefenso, se caracteriza por ser veloz, inconstante y perfectamente controlable, pese a la repugnancia que ocasione (Chevalier y Gheerbrant 1995).

Al entender el proceso de amor como una entrega absoluta al otro, si el otro es visto como un animal, el yo no puede dejar de serlo. Por este motivo, recuérdese, la misma escritora también se trata a sí misma como determinados animales en algunas de sus cartas, en concreto, de rata (carta 49), de buitra (carta 55) y de borriquita (carta 55). Parece claro que las connotaciones de estos animales han de entenderse de forma positiva, lo que implica dar la vuelta a la negatividad que puede cada uno de ellos ofrecer de forma descontextualizada en los distintos sistemas simbólicos (Chevalier y Gheerbrant 1995).

De este modo, la rata, normalmente asociada con la miseria y la avaricia, puede reinterpretarse como una tacañería de amor transformada en animal, que pretende defender la exclusiva posesión del ratonciño que es Benito Pérez Galdós. En la misma línea, el buitre, carroñero por antonomasia, puede interpretarse aquí como un animal que no va a dejar escapar a su presa, pues esencialmente esta está muerta, lo que implica, por un lado, una feroz lucha 
(de amor) por ella con otros de su misma especie y, por otro lado, una consideración revitalizante que asegura la renovación del ciclo vital, pues Emilia da constantes ánimos a su lector para que continúe adelante ("yo sé que debería pedir a V. consejo, porque V. puede superarlo todo", carta 4). El burro, en femenino y derivado con un sufijo diminutivo, connota normalmente la ignorancia, lo que parece encajar con la aparente consideración que la escritora hace de sí misma en el contexto que nos ocupa, pues se siente incapaz de explicarle al lector lo que pretende, si bien la interpretación positiva se encuentra, por un lado, en el cariñoso diminutivo y, por otro lado, en la idea de que ella eleva la imagen social de él que, al fin y al cabo, sigue siendo su maestro.

El realismo es, en cambio, el que parece guiar la relación entre Rosalía de Castro y Manuel Murguía. Ella se llama a sí misma por su propio nombre (Rosalía) o con una abreviatura básica $(R o s a)$, pero no se considera en esencia una persona distinta. Rosalía, en sus cartas, no adopta ningún personaje ni hace que su esposo, el lector de las epístolas, lo adopte. Ella se muestra sencilla, sin disfraces, "tu mujer", "la niña buena", una persona que se presenta ante el interlocutor sin máscaras, enfadada cuando siente que el otro lo merece; molesta, ante lo que considera una injusticia; y enferma, cuando no tiene verdaderas ganas de escribir. Ella es real como la vida misma.

Emilia también se muestra real cuando su trato con el lector se basa en la pura formalidad discursiva, como se deja entrever en la inmensa mayoría de las firmas que plasma en las cartas como "Emilia" o "Emilia Pardo Bazán”. El juego de adoptar personajes como Porcia o Matilde no deja de ser, por un lado, un reto intelectual para el lector y, por otro lado, una manera de justificar su posible disfraz. Un disfraz que, en nuestra opinión, no proviene de su deseo de interpretar un papel artístico mediante las cartas (Panero Menor 1989), sino que se genera porque el camuflaje forma parte del juego del amor.

Esta visión, como decimos, adquiere su culmen en la segunda etapa, naturalmente, pues cuanto más formal es el discurso más lejana es también la relación. Ella, además, no se deja perder fácilmente en el texto, como puede mostrarse en la posible disolución del yo en el tú que tiene lugar durante el proceso de (mutua) animalización. Aunque de cara al lector en el cuerpo del texto se disfrace intentando transformar su vital esencia, en la firma ella siempre es ella, más o menos Emilia, más o menos Pardo Bazán, siempre cumpliendo la función de expresar su yo mediante las estrategias ya vistas como "su amiga verdadera" o "su amiga afectísima": sintagmas nominales cuyos núcleos contienen una fuerza semántica extraordinariamente expresiva y suficientemente potente para impedir que el interlocutor no caiga en sus redes.

La naturaleza enfermiza de Rosalía, finalmente, toma forma en una concepción de la modalidad subjetiva que expresa sobre todo obligación y prohibición externas (nivel morfosintáctico), lo que muestra, mediante las perífrasis analizadas, la debilidad de una mujer que ha pasado toda la vida luchando contra unos elementos que han sido esencialmente incontrolables: una sociedad patriarcal que no la quería como ella deseaba ser y que, por esto, la consideraba extravagante (Barreiro Fernández, 2014); y una naturaleza enfermiza que, sin hacerla necesariamente débil, sí la hizo siempre consciente de la inevitabilidad del fin.

Pese a las similitudes cualitativas encontradas en el análisis perifrástico realizado, Emilia Pardo Bazán es capaz, quizá por su poderío de clase, de convertir las prohibiciones externas en obligaciones internas, asumiendo como identitario lo que no es posible socialmente para una mujer. A diferencia de Rosalía de Castro, ella se encuentra constantemente entre la lucha interior que la obliga a emanciparse y la conciencia exterior que, conservadora, la hace ver que es incapaz de hacerlo (Albert Robatto 2002).

Rosalía y Emilia son, como vemos, dos mujeres plenamente representantes de sus respectivas épocas, que lucharon, cada una a su modo, por encontrar lo que cada individuo desea para ser feliz: su lugar en la sociedad.

\section{Conclusiones}

Hemos visto en el análisis la diferencia en el trato existente entre las cartas de Rosalía de Castro (de las que desearíamos, naturalmente, tener muchísimas más), plagadas de una tierna familiaridad y confianza con su marido y las cartas de Emilia Pardo Bazán, más impregnadas de una pasión amorosa que pasa por distintas fases a lo largo de los años.

La diferencia entre las dos formas de dirigirse a sus respectivos interlocutores, teniendo en cuenta la comparabilidad del corpus por los motivos inicialmente aducidos (pues los dos conjuntos de textos comparten características extrasituacionales, intrasituacionales y 
estructurales-discursivas), es muy profunda, pues incluso en la etapa de la relación Pardo Bazán-Pérez Galdós que más se acerca a la relación claramente conyugal De Castro-Murguía, esta pareja se muestra con un realismo de que carece le idealismo de aquella.

También varía bastante la percepción del interlocutor, más creativa en el caso de la coruñesa que en el caso de la escritora de Padrón: el lector cambia para ella mucho más de lo que su propia imagen cambia para sí misma, pues la creatividad en la firma no es tan amplia como la creatividad en los sintagmas que emplea para dirigirse a Galdós.

La modalidad subjetiva mostrada por las perífrasis verbales es también diferente: Rosalía centra el discurso en lo inevitable de la muerte; Emilia muestra conciencia de las propias limitaciones y ataduras y las utiliza como punto de partida para conseguir lo que se propone, retándose a sí misma a llevar la contraria, por así decirlo, a toda una época.

Como sabemos, el siglo XX no fue justo con ninguna de las dos, pues a principios de la centuria doña Emilia no fue capaz de conseguir un reconocimiento que sin duda merecía y por el que medio país clamaba. Y a mediados de dicho siglo, Rosalía fue ocultada en lo más profundo del armario, como si nunca hubiera existido. Siempre podremos cuestionarnos qué trato habrían recibido ambas... si hubieran nacido varones.

\section{Referencias bibliográficas}

\subsection{Fuentes primarias}

Castro, Rosalía de (1861-1881): Cartas (ed. Consello da Cultura Galega: http://consellodacultura.gal/fondos_documentais/epistolarios/epistolario.php?epistolario=1657.

(1993): Obras completas (ed. Manuel Arroyo Stephens). Madrid: Fundación José Antonio Castro, t. II, pp. 601-614. [Una de las dos ediciones en las que se basa la edición del Instituto Cervantes en: http://www.cervantesvirtual.com/obra-visor/cartas--1/html/feed6a52-82b1-11df-acc7-002185ce6064_2. html\#I_0_].

(1980): Obra completa (ed. Mauro Armiño). Madrid: Akal, t. III, pp. 531-549. [Una de las dos ediciones en las que se basa la edición del Instituto Cervantes: http://www.cervantesvirtual.com/obra-visor/ cartas--1/html/feed6a52-82b1-11df-acc7-002185ce6064_2.html\#I_0 ].

Pardo Bazán, Emilia (2013/1883-1915): «Miquiño mío». Cartas a Galdós (eds. Isabel Parreño y Juan Manuel Hernández). Madrid: Turner.

\subsection{Fuentes secundarias}

Albert Robatto, Matilde (2002): "Rosalía, Murguía y Doña Emilia: Conflicto inevitable", Revista de estudios hispánicos 29/1-2, pp. 245-260.

Almeida Cabrejas, Belén; Rocío Díaz Moreno y María del Carmen Fernández López (eds.) (2017): “Cansada tendré a vuestra excelencia con tan larga carta". Estudios sobre aprendizaje y práctica de la escritura por mujeres en el ámbito hispánico (1500-1900). Lugo: Axac.

Alturo, Núria (2010a): "La referència en la Gramàtica Funcional Discursiva", Sintagma 22, pp. 51-67. (http://www.sintagma.udl.cat/export/sites/Sintagma/documents/articles_22/Alturo.pdf).

(2010b): "Coherencia discursiva: dimensiones contextual, conceptual y gramatical", Círculo de Lingüística Aplicada a la Comunicación 41, pp. 3-30.

Álvarez Ruiz de Ojeda, María Victoria (2016): "Rosalía enferma: Carta de Alfredo Vicenti a Manuel Murguía", Follas novas. Revista de estudos rosalianos 1, pp. 124-143.

Baranda Leturio, Nieves y Anne J. Cruz (eds.) (2018): Las escritoras españolas de la Edad Moderna. Historia y guía para la investigación. Madrid: UNED.

Barreiro Fernández, Xosé Ramón (2014): "A evolución intelectual e política do matrimonio MurguíaCastro, desde os anos sesenta aos anos oitenta do século XIX", en R. Álvarez, A. Angueira, M. do C. Rábade y D. Vilavedra (coords.), Rosalía de Castro no século XXI: Unha nova ollada [actas do congreso desenvolvido en febreiro-xuño 2013]. Santiago de Compostela: Consello da Cultura Galega, pp. 19-38 (DOI: 10.17075/rcsxxi.2014.001).

Beaugrande, Robert y Wolfgang Ulrich Dressler (1997): Introducción a la lingüística del texto. Barcelona: Ariel. Chevalier, Jean y Alain Gheerbrant (1995): Diccionario de los símbolos. Madrid: Herder.

Costa Clavell, Xavier (1967): Rosalía de Castro. Barcelona: Plaza\&Janés.

Cuenca, Maria Josep (2010): Gramática del texto. Madrid: Arco/Libros.

Davies, Catherine (2014): "Rosalía de Castro: la falta de una vida pública. Réplica a la ponencia de Xosé R. Barreiro Fernández", en R. Álvarez, A. Angueira, M. do C. Rábade y D. Vilavedra (coords.), Rosalía 
de Castro no século XXI: Unha nova ollada [actas do congreso desenvolvido en febreiro-xuño 2013]. Santiago de Compostela: Consello da Cultura Galega, pp. 39-46 (DOI: 10.17075/rcsxxi.2014.002).

Fernández de Castro, Félix (1999): Las perifrasis verbales en el español actual. Madrid: Gredos.

Fernández Martín, Patricia (2014): "Perífrases verbais con valor deóntico no discurso paremiolóxico: unha perspectiva diacrónica”, Cadernos de fraseoloxía galega 16, pp. 61-92 (http://www.cirp.gal/pub/docs/ cfg/cfg16_03.pdf).

(2015): "Perífrasis verbales con valor deóntico en el discurso epistolar de santa Teresa de Jesús", en I. Pérez Cuenca, M ${ }^{\mathrm{a}}$ I. Abradelo de Usera y T. Cid Vázquez (coords.), Actas del Congreso Interuniversitario Santa Teresa de Jesús, Maestra de vida. Ávila, del 1 al 3 de agosto de 2015. Ávila: UCAV, pp. 1257-1277 (http://www.congresosantateresa2015.es/downloads/actasCongreso.pdf).

(2016): "El enfoque antropológico en la enseñanza de la historia de la literatura: una propuesta didáctica de metaenseñanza literaria”, Lenguas Modernas 47, pp. 55-74 (https://lenguasmodernas.uchile. cl/index.php/LM/article/view/45184).

(2018): "Del nivel interpersonal al nivel morfosintáctico en algunas cartas de sor María de Jesús de Ágreda", Estudios humanísticos. Filología 40, pp. 41-69 (http://dx.doi.org/10.18002/ehf.v0i40.5449).

Gallego Roca, Miguel (2015): "Francamente, naturalmente: José Ido del Sagrario. El camino desde la novela hacia la historia a través de un personaje chiflado", en X Congreso Internacional Galdosiano, celebrado en Casa Museo Pérez Galdós-Casa de Colón del 18 al 21 de junio de 2013. Las Palmas de Gran Canaria: Cabildo, pp. 198-204 (http://actascongreso.casamuseoperezgaldos.com/index.php/cig/ article/view/9343).

Garachana Camarero, Mar (2017a): "Los límites de una categoría híbrida. Las perífrasis verbales”, en M. Garachana Camarero (ed.), La gramática de la diacronía. La evolución de las perifrasis verbales modales en español. Madrid/Frankfurt, Iberoamericana/Vervuert, pp. 35-80.

- (ed.) (2017b): La gramática de la diacronía. La evolución de las perífrasis verbales modales en español. Madrid/Frankfurt: Iberoamericana/Vervuert.

Halliday, M.A.K y Christian M.I.M. Mathiessen (2014): Halliday's Introduction to Functional Grammar. Kent: Routledge.

Haro Fernández, Ana María de (2011): "La violencia económica de género en la literatura española: el caso de Emilia Pardo Bazán y Benito Pérez Galdós. Notas para un estado de la cuestión”, en I. Vázquez Bermúdez (coord.), Logros y retos: Actas del III congreso universitario nacional "Investigación y género". Sevilla: Universidad, pp. $421-447$ (https://idus.us.es/xmlui/handle/11441/39114).

Hengeveld, Kees y J. Lachlan Mackenzie (2008): Functional Discourse Grammar. A typologically-based theory of language structure. Oxford: Oxford University Press.

Hermida, Carme (1989): "Emilia Pardo Bazán e o rexurdimento", Festa da palabra silenciada. Publicación galega de mulleres 6, pp. 17-23 (http://consellodacultura.gal/mediateca/extras/CCG_ig_pub2001_ Festa-da-Palabra_06.pdf).

Mayoral, Marina (1986): Rosalía de Castro. Madrid: Fundación Juan March-Cátedra.

Nystrand, M.; Margaret Himley y Anne Doyle (1986): The structure of written communication. Studies in Reciprocity between Writers and Readers. Orlando: FL Academic Press.

Panero Menor, Ma Carmen (1989): “Á luz das cartas de amor de Doña Emilia Pardo Bazán”, Festa da palabra silenciada. Publicación galega de mulleres 6, pp. $40-44$ (http://consellodacultura.gal/mediateca/ extras/CCG_ig_pub2001_Festa-da-Palabra_06.pdf).

Patiño Eirín, Cristina (2013): "Fundamentos rusos de Salvador Monsalud como hombre superfluo", en Actas del décimo congreso internacional Galdosiano. Las Palmas de Gran Canaria: Cabildo Insular de Gran Canaria,pp. 147-156 (https://mdc.ulpgc.es/cdm/ref/collection/galdosianos/id/1246).

Sáez Rivera, Daniel M. (2014b): "The Interplay of Object Clitic Doubling and the Grammaticalization of Address Forms in the Genre of Collections of Letters in Spanish" en J. L. Girón Alconchel y D. M. Sáez Rivera (eds.): Procesos de gramaticalización en la historia del español. Madrid/Frankfurt: Iberoamericana/Vervuert, pp. 321-360.

Salzmann, Zdenek (2007): Language, Culture and Society. An Introduction to Linguistic Anthropology. Oxford: Westview Press.

Traugott, Elisabeth Closs y Richard B. Dasher (2002): Regularity in Semantic Change. Cambridge: Cambridge University Press.

Van Dijk, Teun A. (2008): Discourse and Context: A Sociocognitive Approach. Cambridge: CUP.

Veyrat Rigat, Montserrat (1993): Aspecto, perifrasis y auxiliación: un enfoque perceptivo. Valencia: Universitat de Valéncia.

Virtanen, Ricardo (2016): “Abril de 1912: fin del sueño de Emilia Pardo Bazán por conquistar una plaza en la Real Academia Española de la Lengua", La Tribuna. Cadernos de Estudos da Casa-Museo Emilia Pardo Bazán 11, pp. 23-45 (http://revistalatribuna.gal/index.php/TRIBUNA/article/view/229/244). 